\title{
Efficient breeding of industrial brewing yeast strains using CRISPR/ Cas9-aided mating-type switching
}

\author{
Kristoffer Krogerus $^{1}$ [D $\cdot$ Eugene Fletcher $^{2} \cdot$ Nils Rettberg $^{3} \cdot$ Brian Gibson $^{4} \cdot$ Richard Preiss $^{2}$
}

Received: 11 July 2021 / Revised: 26 September 2021 / Accepted: 28 September 2021 / Published online: 13 October 2021

(c) The Author(s) 2021, corrected publication 2022

\begin{abstract}
Yeast breeding is a powerful tool for developing and improving brewing yeast in a number of industry-relevant respects. However, breeding of industrial brewing yeast can be challenging, as strains are typically sterile and have large complex genomes. To facilitate breeding, we used the CRISPR/Cas9 system to generate double-stranded breaks in the MAT locus, generating transformants with a single specified mating type. The single mating type remained stable even after loss of the Cas9 plasmid, despite the strains being homothallic, and these strains could be readily mated with other brewing yeast transformants of opposite mating type. As a proof of concept, we applied this technology to generate yeast hybrids with an aim to increase $\beta$-lyase activity for fermentation of beer with enhanced hop flavour. First, a genetic and phenotypic pre-screening of 38 strains was carried out in order to identify potential parent strains with high $\beta$-lyase activity. Mating-competent transformants of eight parent strains were generated, and these were used to generate over 60 hybrids that were screened for $\beta$-lyase activity. Selected phenolic off-flavour positive $(\mathrm{POF}+)$ hybrids were further sporulated to generate meiotic segregants with high $\beta$-lyase activity, efficient wort fermentation, and lack of POF, all traits that are desirable in strains for the fermentation of modern hop-forward beers. Our study demonstrates the power of combining the CRISPR/Cas9 system with classic yeast breeding to facilitate development and diversification of brewing yeast.
\end{abstract}

Key points

- CRISPR/Cas9-based mating-type switching was applied to industrial yeast strains.

- Transformed strains could be readily mated to form intraspecific hybrids.

- Hybrids exhibited heterosis for a number of brewing-relevant traits.

Keywords Brewing $\cdot$ Breeding $\cdot$ Strain development $\cdot$ Hybrid $\cdot$ Thiol $\cdot$ Beta-lyase

\section{Introduction}

The number of breweries and beer brands globally has expanded dramatically in recent decades (Garavaglia and Swinnen 2018). Consumers are also demanding higher product quality and beer with novel and diverse flavours

Kristoffer Krogerus

kristoffer.krogerus@vtt.fi

1 VTT Technical Research Centre of Finland, Tietotie 2, P.O. Box 1000, 02044 VTT Espoo, Finland

2 Escarpment Laboratories, Guelph, ON, Canada

3 Research Institute for Beer and Beverage Analysis, Versuchs- Und Lehranstalt Für Brauerei in Berlin (VLB) E.V, Seestr. 13, 13353 Berlin, Germany

4 Chair of Brewing and Beverage Technology, Technische Universität Berlin, Berlin, Germany
(Aquilani et al. 2015; Carbone and Quici 2020; Gonzalez Viejo and Fuentes 2020). As much of beer flavour is yeastderived (Holt et al. 2019), brewers may meet this demand and keep ahead of competition by diversifying their products through the use of different yeast strains. While a large and diverse range of yeast strains are naturally available, recent studies have shown that the vast majority of industrially used brewing strains group into one of two domesticated clades (Gallone et al. 2016; Gonçalves et al. 2016; Peter et al. 2018). These strains have evolved to efficiently ferment the complex sugars available in brewer's wort. Non-brewing strains may therefore have difficulties completing fermentation in wort. Yeast breeding and hybridization has been shown to be a promising tool for developing and improving brewing yeast in a number of industry-relevant respects (Steensels et al. 2014; Krogerus et al. 2015, 2016; Mertens et al. 2015). It allows for the combination and enhancement 
of phenotypic traits from diverse sets of strains. Hybrids between Saccharomyces cerevisiae brewing strains and wild Saccharomyces strains, for example, have shown both efficient wort fermentation and a more diverse aroma profile (Mertens et al. 2015; Nikulin et al. 2018). However, brewing strains of S. cerevisiae, especially those in the 'Beer 1'/'Ale beer' group, are typically sterile, which impedes their use in yeast breeding (Gallone et al. 2016; De Chiara et al. 2020; Shimoi et al. 2020).

Yeast breeding relies on the formation and interaction of mating-competent cells (Herskowitz 1988; Neiman 2011; Merlini et al. 2013). Mating-competent cells may form when a diploid MATa/MAT $\alpha$ cell undergoes meiosis and produces haploid spores of either MATa or MAT $\alpha$ mating type. When two cells of opposite mating type come in contact with each other, they can undergo mating and cell fusion. Haploid cells may also switch mating type following the repair of a double-stranded break (DSB) created by the HO endonuclease at the mating-type locus (Haber 2012). As the $\mathrm{HO}$ gene is repressed in diploid (or polyploid) cells heterozygous for the mating-type locus (MATa/MAT $\alpha$ ), their mating type remains stable. Such cells can, however, on rare occasions undergo loss of heterozygosity at the mating-type locus, which results in the formation of non-haploid mating-competent cells with a single mating type (Gunge and Nakatomi 1972; Hiraoka et al. 2000). This is often exploited for breeding of sterile strains, such as brewing strains, in a process called 'rare mating' (Krogerus et al. 2017). However, spontaneous loss of heterozygosity events occurs at low frequencies $\left(<10^{-4}\right)$, and parent strains require selection markers to allow selection of successful crosses. Obtaining hybrids with industrial brewing strains can therefore be challenging and time-consuming.

To overcome these limitations, a number of engineering techniques have been developed to facilitate breeding of sterile yeast strains. Alexander et al. (2016) describe a technique that can be used to force mating-type change in $M A T \mathbf{a} / M A T \alpha$ cells by transformation with a plasmid carrying the $H O$ gene under the control of an inducible promoter and a drug-resistance marker. Fukuda et al. (2016) describe another approach, where MATa/MAT $\alpha$ cells are transformed with a plasmid carrying either the $a 1$ or $\alpha 2$ gene from the mating-type locus together with drug-resistance markers with promoters specific to either the MATa 1 or MAT 22 gene products. Recently, the CRISPR/Cas9 system was also used to force mating-type changes in diploid cells by creating DSBs in the mating-type locus using a Cas9 enzyme (Xie et al. 2018). As the approach was, to our knowledge, only tested on heterothallic (ho) laboratory strains with a maximum ploidy of two, we wished to explore whether it could be applied to industrial brewing strains, which are homothallic and aneuploid (often with DNA contents close to tetraploid).
In this study, we therefore applied the CRISPR-based mating-type switching process developed by Xie et al. (2018) to industrial brewing strains in the hope of isolating variants with a stable single mating type. Furthermore, we ultimately wanted to use these stable single mating-type variants to readily generate hybrids between industrial brewing strains. As a proof of concept, we aimed to generate yeast hybrids with increased $\beta$-lyase activity for fermentation of beer with enhanced hop flavour from released thiols. Recent studies have highlighted the important contribution of volatile thiols to fruity hop aroma in beer (Gros et al. 2012; Cibaka et al. 2017; Dennenlöhr et al. 2020). These compounds are present in minute amounts but are still perceivable thanks to low odour thresholds (Holt et al. 2019). In addition to these free thiols, a large fraction of the total thiols in hops are found in glutathionylated or cysteinylated form (Gros et al. 2012; Roland et al. 2016). These conjugated thiols do not impact aroma by themselves, but may transfer to wort during the brewing process. Therein, a volatile thiol may be enzymatically released from the conjugated thiol through $\beta$-lyase activity (Roncoroni et al. 2011). Hence, a beer fermented with a yeast strain high in $\beta$-lyase activity is expected to contain higher levels of volatile thiols than one from a strain with low activity.

Here, a set of 38 S. cerevisiae strains were first phenotypically and genetically screened in order to identify potential parent strains with high $\beta$-lyase activity. We then generated mating-competent transformants of eight parent strains with either MATa or MAT $\alpha$ mating types. These were then used to generate over 60 hybrids that were screened for $\beta$-lyase activity. As multiple parent strains were $\mathrm{POF}+$ (phenolic off-flavour positive, i.e. being able to convert ferulic acid to 4-vinylguaiacol), a selection of hybrids was further sporulated to generate meiotic segregants lacking the POF trait. A range of hybrid segregants were obtained with high $\beta$-lyase activity, efficient wort fermentation, and lack of POF, all traits that are desirable in strains for the fermentation of modern hopforward beers. Our study demonstrates the power of combining the CRISPR/Cas9 system with classic yeast breeding to facilitate development and diversification of brewing yeast.

\section{Materials and methods}

\section{Yeast strains}

A list of strains used in this study is available in Supplementary Table S1.

\section{High-throughput phenotypic assays}

$\beta$-lyase activity was estimated by measuring growth on various nitrogen sources containing carbon-sulphur bonds: 
cysteine, $S$-methylcysteine, and cys-4MMP (4-(4-methylpentan-2-one)-1-cysteine; synthesized according to Howell et al. (2004)). Media contained $0.17 \%$ Yeast Nitrogen Base without $\left(\mathrm{NH}_{4}\right)_{2} \mathrm{SO}_{4}$ and amino acids, $1 \%$ glucose, $0.01 \%$ pyridoxal 5-phosphate, and $15 \mathrm{mM}$ of the above listed nitrogen sources. Growth assays were carried out in 96-well plates, with $145 \mu \mathrm{L}$ media per well. Wells were inoculated (to a starting OD600 value of 0.1 ) with $5 \mu \mathrm{L}$ of washed preculture suspended in water to an OD600 value of 3. Plates were sealed with a Breathe-Easy membrane (Sigma-Aldrich, Espoo, Finland) and incubated at $25^{\circ} \mathrm{C}$ for 1 week. OD600 values were measured on a VarioSkan plate reader (Thermo Scientific, Vantaa, Finland), while cysteine content of the growth media was estimated using DTNB (Ellman 1958).

The ability to produce phenolic off-flavour was estimated using the absorbance-based method described by Mertens et al. (2017).

Micro-scale wort fermentations were carried out in Greiner deep-well plates containing $700 \mu \mathrm{L}$ of $15^{\circ} \mathrm{P}$ wort. Yeast was inoculated to a starting OD600 of 0.1 from washed pre-culture suspended in water to an OD600 value of 3. Fermentations were carried out for 4 days at $25{ }^{\circ} \mathrm{C}$, after which the plates were centrifuged and the supernatant was analysed by HPLC for fermentable sugars and ethanol.

\section{Cas9 plasmid construction and yeast transformations}

Plasmid construction was carried out using the plasmid pCC-036 as backbone (Rantasalo et al. 2018). pCC-036 contains yeast codon-optimized Cas 9 expressed under TDH3p, guiding RNA (gRNA) expressed under $S N R 52 p$ and $h y g R$ for selection on hygromycin. The two gRNA protospacer sequences, GTTCTAAAAATGCCCGTGCT and CAA ATCATACAGAAACACAG, were obtained from Xie et al. (2018) and target MATa and MAT $\alpha$, respectively. A synthetic DNA fragment with the gRNA sequence was ordered from Integrated DNA Technologies (Leuven, Belgium) as a gBlock and introduced into the plasmid with restriction enzyme-based techniques (Thermo Scientific, Vantaa, Finland). The ligated plasmid was transformed into Escherichia coli TOP 10 by electroporation, and plasmid correctness was confirmed by Sanger sequencing.

Yeast transformations were performed using an optimized stationary phase transformation protocol (Tripp et al. 2013). Overnight yeast cultures were pelleted and incubated with $100 \mathrm{mM}$ DTT (dithiothreitol) for $20 \mathrm{~min}$ at $42{ }^{\circ} \mathrm{C}$. A lithium acetate-based transformation mix was added, together with $1 \mu \mathrm{g}$ of purified plasmid, and cells were transformed at $42{ }^{\circ} \mathrm{C}$ for $40 \mathrm{~min}$. The transformed cells were selected on plates containing $400 \mathrm{mg} / \mathrm{L}$ hygromycin B (Sigma-Aldrich, Espoo, Finland). Successful mating-type change was determined by PCR as described below. Colonies from selection plates were streaked for single colonies three successive times on YPD agar plates before further use to encourage plasmid loss, after which they were stored at $-80^{\circ} \mathrm{C}$.

\section{PCR to confirm mating-type change and hybridizations}

The mating-type locus was amplified with PCR using the previously published primers: MAT-R (AGTCACATCAAG ATCGTTTATGG), MATa-F (ACTCCACTTCAAGTAAGA GTTTG), and MAT $\alpha-F$ (GCACGGAATATGGGACTA CTTCG) (Huxley et al. 1990). These primers amplify a 404bp fragment for MAT $\alpha$ and a 544-bp fragment for MATa. In addition, the presence of $H M L \alpha$ (new primers designed) and HMRa (Ota et al. 2018) was tested using the following primers: HML $\alpha-\mathrm{F}$ (GAATGGCACGCGGACAAAAT), HML $\alpha-R$ (TGGAACACAGAAAAGAGCAGTG), HMRa-F (GTTGCAAAGAAATGTGGCATTACTCCA), and HMRaR (AGCTTTCTCTAACTTCGTTGACAAA). Interdelta fingerprints were produced using delta12 and delta21 primers from Legras and Karst (2003). PCR reactions were carried out with Phusion High-Fidelity PCR Master Mix with HF Buffer (Thermo Scientific, Vantaa, Finland) and primer concentrations of $0.5 \mu \mathrm{M}$. PCR products were separated and visualized on $1.0 \%$ agarose gels or on an Agilent ZAG DNA Analyser capillary electrophoresis device (Agilent, Santa Clara, CA, USA).

\section{Hybridizations and selection of meiotic segregants}

Hybridizations between mating-competent variants were attempted by placing cells of both parent strains, with opposite mating types, adjacent to each other on a YPD agar plate with the aid of a MSM400 dissection microscope (Singer Instruments, Roadwater, UK). Plates were incubated at $25{ }^{\circ} \mathrm{C}$ for up to 5 days, after which any emerging colonies were replated twice on fresh YPD plates to ensure single colony isolates. PCR of the mating-type locus and interdelta fingerprints were used to confirm successful hybridization.

Selected hybrids were transferred to $1 \%$ potassium acetate agar for sporulation. After 7 days of incubation at $25^{\circ} \mathrm{C}$, ascospores were digested (using Zymolyase $100 \mathrm{~T}$ (US Biological, Salem, MA, USA)) and dissected on YPD agar using the MSM400 dissection microscope (Singer Instruments, Roadwater, UK).

\section{IRC7 copy number estimation by qPCR}

The relative copy numbers of the $I R C 7$ gene in selected strains were estimated with quantitative PCR of genomic DNA. Primers PF6 and PR7 from Roncoroni et al. (2011) were used for $I R C 7$. Copy numbers were normalized to that of $A L G 9$ and $U B C 6$ (primers listed in Krogerus et al. 
(2019)). The efficiencies (E) of the qPCR assays (ranging from 1.9 to 1.94) for each primer pair were calculated using the formula $10(-1 / m)$, where $m$ is the slope of the line of the threshold cycle (CT)-versus-log dilution plot of the DNA template ( 8 pg to 8 ng input DNA) (Pfaffl 2001). The qPCR reactions were prepared with PerfeCTa SYBR ${ }^{\circledR}$ Green SuperMix (QuantaBio, Beverly, MA, USA) and $0.3 \mu \mathrm{M}$ of the primers. The qPCR reactions were performed on a LightCycler® 480 II instrument (Roche Diagnostics, Basel, Switzerland) in four technical replicates on $1 \mathrm{ng}$ template DNA. The following programme was used: pre-incubation $\left(95{ }^{\circ} \mathrm{C}\right.$ for $3 \mathrm{~min}$ ), amplification cycle repeated 45 times $\left(95{ }^{\circ} \mathrm{C}\right.$ for $15 \mathrm{~s}, 60{ }^{\circ} \mathrm{C}$ for $30 \mathrm{~s}, 72^{\circ} \mathrm{C}$ for $20 \mathrm{~s}$ with a single fluorescence measurement), melting curve programme (65-97 ${ }^{\circ} \mathrm{C}$ with continuous fluorescence measurement), and finally a cooling step to $40{ }^{\circ} \mathrm{C}$. The copy numbers of $I R C 7$ relative to $A L G 9$ and $U B C 6$ were calculated using the Pfaffl method (Pfaffl 2001).

\section{DNA content by flow cytometry}

Ploidy of selected strains was measured using SYTOX Green staining and flow cytometry as described previously (Krogerus et al. 2017).

\section{Whole genome sequencing and analysis}

For analysis of the parent strains, sequencing reads were first obtained from NCBI-SRA (accession numbers in Supplementary Table S1). Reads were trimmed and filtered with fastp using default settings (version 0.20.1; Chen et al. 2018). Trimmed reads were aligned to a $S$. cerevisiae S288C reference genome (Engel et al. 2014) using BWAMEM (Li and Durbin 2009), and alignments were sorted, and duplicates were marked with sambamba (version 0.7.1; Tarasov et al. 2015). Variants were jointly called in all strains using FreeBayes (version 1.32; Garrison and Marth, 2012). Variant calling used the following settings: -minbase-quality 30 -min-mapping-quality 30 -min-alternatefraction 0.25 -min-repeat-entropy 0.5 -use-best-n-alleles 70 $-p 2$. The resulting VCF file was filtered to remove variants with a quality score less than 1000 and with a sequencing depth below 10 per sample using BCFtools (Li 2011). Variants were annotated with SnpEff (Cingolani et al. 2012).

For phylogenetic analysis, the variants were filtered to retain only single nucleotide polymorphisms and remove sites with a minor allele frequency less than $5 \%$. The filtered SNP matrix was converted to PHYLIP format (https:// github.com/edgardomortiz/vcf2phylip). A random allele was selected for heterozygous sites. A maximum likelihood phylogenetic tree was generated using IQ-TREE (version 2.0.3;
Nguyen et al. 2015) run with the 'GTR + G4' model and 1000 bootstrap replicates (Minh et al. 2013).

Four hybrid strains were whole genome sequenced at NovoGene (UK). DNA was extracted using the method described by Denis et al. (2018). Sequencing was carried out on an Illumina NovaSeq 6000 instrument. The $150 \mathrm{bp}$ paired-end reads have been submitted to NCBISRA under BioProject number PRJNA740182. Analysis of the hybrid strains was carried out essentially as described above. Sequencing coverage was estimated with mosdepth (version 0.2.6; Pedersen and Quinlan 2018). Chromosome copy numbers were estimated based on distribution of alternate allele frequencies, ploidy as measured by flow cytometry, and sequencing coverage.

\section{Wort fermentations}

Lab-scale wort fermentations were first carried out in triplicate to screen the yeast hybrids in order to identify top-performing strains that were able to rapidly attenuate wort sugars. To do this, overnight cultures of the yeast hybrids were set up by inoculating single colonies in $10 \mathrm{~mL}$ wort. These were then incubated at $25{ }^{\circ} \mathrm{C}$ with shaking $(120 \mathrm{rpm})$ for $24 \mathrm{~h}$. The optical density $\left(\mathrm{OD}_{600}\right)$ of the overnight cultures was measured, and the cultures were diluted into $400 \mathrm{~mL} 10^{\circ} \mathrm{P}$ wort (made from pale barley malt and $2.4 \mathrm{~g} \mathrm{~L}^{-1}$ of Cascade hops) in $500-\mathrm{mL}$ glass bottles to a starting OD600 value of 0.3 as previously described by Mertens et al. (2015). The bottles were fitted with airlocks and were incubated at $25{ }^{\circ} \mathrm{C}$. Specific gravity readings of the fermenting wort were taken daily for 7 days using the DMA 35 handheld density metre (Anton Paar GmbH, Graz, Austria).

$2 \mathrm{~L}$-scale wort fermentations were carried out in $3-\mathrm{L}$ cylindroconical stainless steel fermenting vessels, containing $2 \mathrm{~L}$ of $15^{\circ} \mathrm{P}$ wort. Yeast was propagated in autoclaved wort. The $15^{\circ} \mathrm{P}$ wort $(70.5 \mathrm{~g}$ maltose, $21 \mathrm{~g}$ maltotriose, $19 \mathrm{~g}$ glucose, and $4.6 \mathrm{~g}$ fructose per litre) was produced at the VTT Pilot Brewery from barley malt and contained $2.5 \mathrm{~g} \mathrm{~L}^{-1}$ each of Cascade and Perle hops added to the whirlpool. The wort was oxygenated to $10 \mathrm{mg} \mathrm{L}^{-1}$ prior to pitching (Oxygen Indicator Model 26,073 and Sensor 21,158; Orbisphere Laboratories, Geneva, Switzerland). Yeast was inoculated at a rate of $15 \times 10^{6}$ viable cells $\mathrm{mL}^{-1}$, together with $2.5 \mathrm{~g} \mathrm{~L}^{-1}$ each of Cascade and Perle hops (dry hopping). The fermentations were carried out in triplicate at $20{ }^{\circ} \mathrm{C}$ until no change in alcohol level was observed for $24 \mathrm{~h}$ or for a maximum of 9 days.

Wort samples were drawn regularly from the fermentation vessels aseptically and placed directly on ice, after which the yeast was separated from the fermenting wort by centrifugation $\left(9000 \times g, 10 \mathrm{~min}, 1{ }^{\circ} \mathrm{C}\right)$. 


\section{Beer chemical analysis}

The specific gravity, alcohol level (\% v/v), and $\mathrm{pH}$ of samples were determined from the centrifuged and degassed fermentation samples using an Anton Paar Density Metre DMA $5000 \mathrm{M}$ with Alcolyzer Beer ME and pH ME modules (Anton Paar GmbH, Graz, Austria).

Concentrations of fermentable sugars (glucose, fructose, maltose, and maltotriose) and ethanol were measured by HPLC using a Waters 2695 Separation Module and Waters System Interphase Module liquid chromatograph coupled with a Waters 2414 differential refractometer (Waters Co., Milford, MA, USA). An Aminex HPX-87H Organic Acid Analysis Column $(300 \times 7.8 \mathrm{~mm}$; Bio-Rad, Hercules, CA, USA) was equilibrated with $5 \mathrm{mM} \mathrm{H}_{2} \mathrm{SO}_{4}$ (Titrisol, Merck, Darmstadt, Germany) in water at $55{ }^{\circ} \mathrm{C}$, and samples were eluted with $5 \mathrm{mM} \mathrm{H}_{2} \mathrm{SO}_{4}$ in water at a $0.3 \mathrm{~mL} \mathrm{~min}^{-1}$ flow rate.

Higher alcohols and esters were determined by headspace gas chromatography with flame ionization detector (HS-GC-FID) analysis. Four-millilitre samples were filtered $(0.45 \mu \mathrm{m})$ and incubated at $60{ }^{\circ} \mathrm{C}$ for $30 \mathrm{~min}$, and then $1 \mathrm{~mL}$ of gas phase was injected (split mode; $225^{\circ} \mathrm{C}$; split flow of $30 \mathrm{~mL} \mathrm{~min}^{-1}$ ) into a gas chromatograph equipped with an FID detector and headspace autosampler (Agilent 7890 Series; Palo Alto, CA, USA). Analytes were separated on a HP-5 capillary column $(50 \mathrm{~m} \times 320 \mu \mathrm{m} \times 1.05 \mu \mathrm{m}$ column; Agilent, USA). The carrier gas was helium (constant flow of $1.4 \mathrm{~mL} \mathrm{~min}^{-1}$ ). The temperature programme was $50{ }^{\circ} \mathrm{C}$ for $3 \mathrm{~min}, 10^{\circ} \mathrm{C} \mathrm{min}^{-1}$ to $100^{\circ} \mathrm{C}, 5^{\circ} \mathrm{C} \mathrm{min}^{-1}$ to $140{ }^{\circ} \mathrm{C}$, and $15^{\circ} \mathrm{C} \mathrm{min}{ }^{-1}$ to $260^{\circ} \mathrm{C}$ and then isothermal for $1 \mathrm{~min}$. Compounds were identified by comparison with authentic standards and were quantified using standard curves. 1-Butanol was used as internal standard.

4-Vinylguaiacol was analysed using HPLC based on methods described by Coghe et al. (2004) and McMurrough et al. (1996). The chromatography was carried out using a Waters Alliance HPLC system consisting of a Waters e2695 Separations Module equipped with a XTerra ${ }^{\circledR}$ MS C18 column $(5 \mu \mathrm{m}, 4.6 \times 150 \mathrm{~mm})$ and a Waters 2996 Photodiode Array Detector (Waters Co., Milford, MA, USA). The mobile phase consisted of $\mathrm{H}_{2} \mathrm{O} / \mathrm{CH}_{3} \mathrm{OH} / \mathrm{H}_{3} \mathrm{PO}_{4}(64: 35: 1$, v/v), and flow rate was $0.5 \mathrm{~mL} \mathrm{~min}{ }^{-1}$. The diode array detector was used at 190-400 nm. 4-Vinylguaiacol was quantified at $260 \mathrm{~nm}$ using standard curves of the pure compound (0.3-10 $\left.\mathrm{mg} \mathrm{L}^{-1}\right)$.

The volatile thiols 4-mercapto-4-methyl-2-pentanone (4MMP), 3-mercapto-1-hexanol (3MH), and 3-mercaptohexylacetate (3MHA) were determined using the method described by Dennenlöhr et al. (2020). In this method, thiols are extracted and derivatized by headspace solid-phase microextraction (HS-SPME) with on-fibre derivatization (OFD) using 2,3,4,5,6-pentafluorobenzyl bromide (PFBBr).
Resulting PFBBr-thioesters are then separated and analysed using gas chromatography tandem mass spectrometry (GC-MS/MS). The instrumental setup, parameters of sample preparation, GC-MS/MS analysis, calibration, and quantification were in full accordance to Dennenlöhr et al. (2020). Each sample was analysed in duplicate.

Flocculation of the yeast strains was determined using a modified Helm's test (D'Hautcourt and Smart 1999; Krogerus et al. 2015).

\section{Data visualization and analysis}

Data and statistical analyses were performed with R (http:// www.r-project.org/). The phylogenetic tree was produced using the 'ggtree' package (Yu et al. 2017). Flow cytometry data was analysed with 'flowCore' (Hahne et al. 2009) and 'mixtools' (Benaglia et al. 2009) packages. Scatter and box plots were produced with the 'ggpubr' package (Kassambara 2020). Variants along the genome were visualized in $R$ using the 'karyoploter' package (Gel and Serra 2017).

\section{Results}

\section{Identifying suitable parent strains for improving $\beta$-lyase activity}

As the aim of the applied part of this study was to obtain brewing yeast strains with improved $\beta$-lyase activity, we first performed a phenotypic and genetic pre-screening step to identify suitable parent strains to use for the CRISPR-mediated hybridizations. A set of thirty-eight Saccharomyces cerevisiae strains were included in the screening (strain names and unique numbers are listed in Supplementary Table S1). Thirty-seven of these were brewing strains from Escarpment Laboratories, while the final strain, YJM1400 (or SACE_ YCM), was selected from the 1,011 yeast genomes study (Peter et al. 2018). YJM1400 was originally isolated from guava fruit in the Philippines and belongs to the ' 24 Asian Islands' phylogenetic clade in Peter et al. (2018). This strain was included here, as we predicted it to have a high $\beta$-lyase activity based on its IRC7 sequence and copy number. The main $\beta$-lyase enzyme in S. cerevisiae is encoded by the IRC7 gene (Roncoroni et al. 2011; Ruiz et al. 2021). YJM1400 not only carries the more active full-length allele of $I R C 7$ (Roncoroni et al. 2011), but also lacks any of the widespread inactivating mutations that have recently been identified (Cordente et al. 2019), and appears to be one of the few strains in the 1,011 yeast genomes study with enhanced IRC7 copy number.

Using whole genome sequence data, we first queried the presence and allele frequency of inactivating mutations (Cordente et al. 2019) in IRC7 among the 38 strains. The 
allele frequency describes how many out of all IRC7 alleles carry the specific mutation, and here, it varied considerably because of differences in ploidy level among the strains. The long allele of $I R C 7$ was present in most strains, while the Thr185Ala missense mutation was common among the brewing strains (Fig. 1). The Thr185Ala mutation could be found, for example, among all strains in the 'UK' sub-clade, where it was often homozygous. Other inactivating mutations were also frequent among the tested strains, including Lys43Arg, Tyr56*, His197Gln, and Val348Leu (Cordente et al. 2019; Curtin et al. 2020). Only a handful of strains lacked any of the known inactivating mutations, and these were thus predicted to have a higher $\beta$-lyase activity. In addition to $I R C 7$, we queried for the presence of loss-offunction mutations in URE2, which encodes a regulatory protein involved in nitrogen catabolite repression, which reduces $I R C 7$ expression (Thibon et al. 2008; Dufour et al. 2013). A group of five brewing strains were found to contain a heterozygous nonsense mutation in URE2 (Fig. 1). Presence of inactivating mutations in URE2 has been shown to increase volatile thiol release during wine fermentations (Dufour et al. 2013).

In addition to the genetic pre-screening, the $\beta$-lyase activity of the strains was estimated by testing their growth on various cysteine-conjugates as sole nitrogen source and by scoring aroma intensity after fermentation in wort supplemented with Cys-4MMP. In general, there was good agreement between the phenotype and genotype, as the best performing strains (e.g. YJM1400, St. Lucifer, Spooky Saison, Ardennes, and Ebbegarden) were those without inactivating mutations or with low-frequency heterozygous inactivating mutations (e.g. Val384Leu at an allele frequency of 0.25

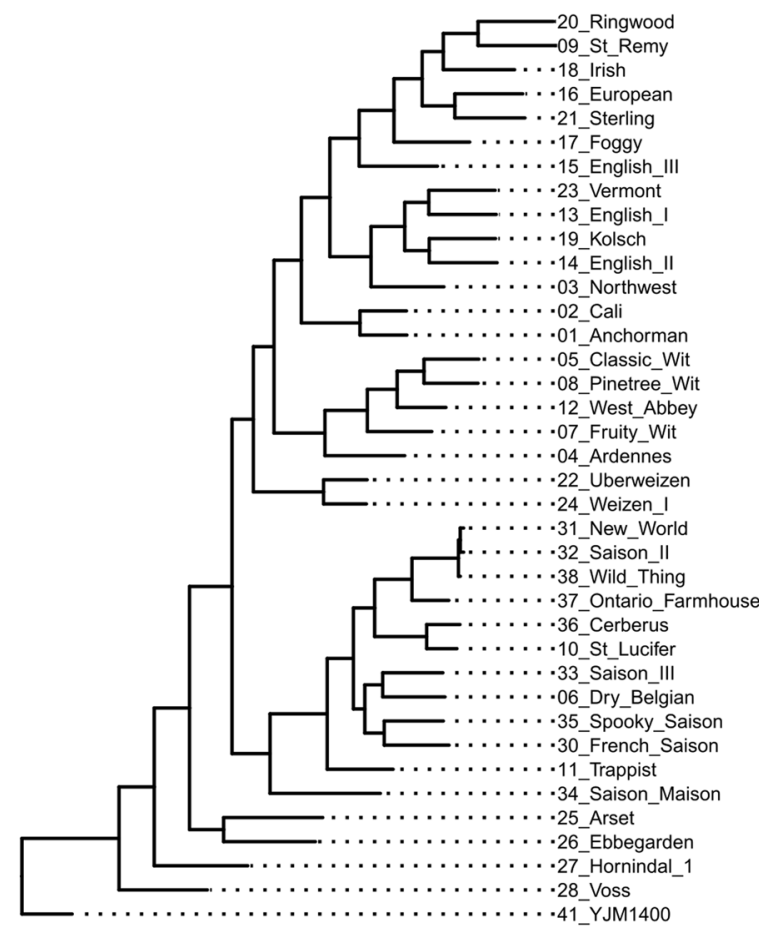

Fig. 1 Genetic and phenotypic screening of $\beta$-lyase activity in the 38 Saccharomyces cerevisiae included in the study. Strains are ordered based on phylogenetic relationship (maximum likelihood phylogenetic tree based on SNPs at 114,700 sites, rooted with $S$. cerevisiae YJM1400 as outgroup). The phenotypic heatmap is coloured blue to red based on Z-scores. Phenolic off-flavour status (white: nega-

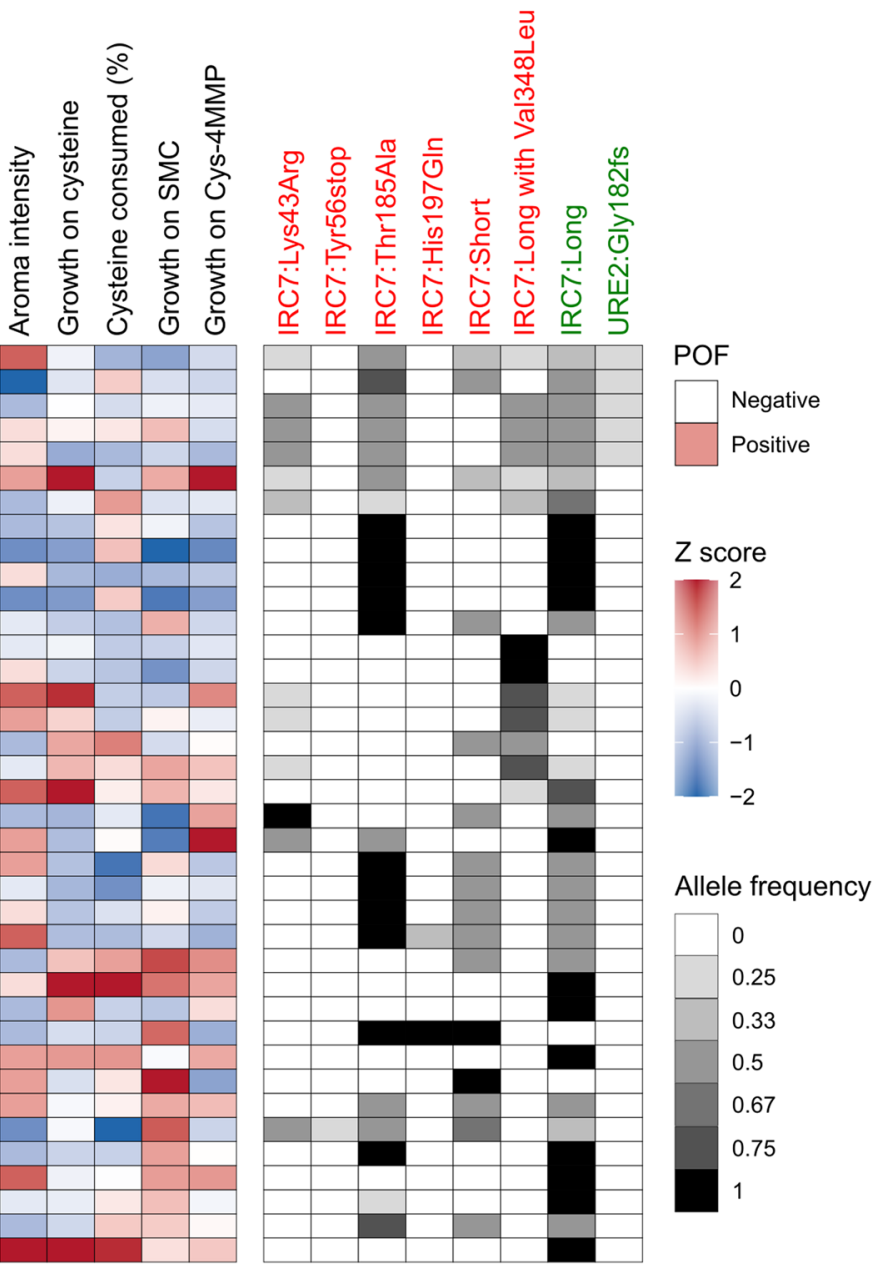

tive, red: positive) of the strains is also indicated. The genotypic heatmap is coloured from white to black based on allele frequency of the different mutations. The mutations that are coloured red have been shown to decrease $\beta$-lyase activity, while the mutations coloured green have been shown to increase $\beta$-lyase activity 
in Ardennes). For strains containing a homozygous long allele of $I R C 7$, significantly higher growth on cysteine and aroma intensity from wort supplemented with Cys-4MMP was observed in strains without any inactivating mutations compared to those with homozygous inactivating mutations (Supplementary Fig. S1). Between phenotypes, moderate positive correlation was also observed between many of the measured phenotypes (Supplementary Table S2).

Based on these pre-screenings, we selected eight candidate parent strains for the hybridization trials (Table 1). Four of these were selected based on high predicted $\beta$-lyase activity in the pre-screenings, and they included YJM1400, St. Lucifer, Ardennes, and Classic Wit. As the end goal was to develop yeast strains suitable for the production of IPAstyle (India Pale Ale) beers, where phenolic off-flavours are unwanted, the remaining four strains were selected among the pool of POF- strains. These strains were Cerberus, Ebbegarden, Foggy London, and Sterling. The selection was based on a combination of predicted $\beta$-lyase activity with other criteria that were relevant to industrial performance, including fermentation speed, attenuation, flocculation, and popularity in the industry (data from Escarpment Laboratories). Next, we attempted to generate mating-competent variants of these eight strains using the CRISPR/Cas9 system.

\section{Generating mating-competent variants for hybridization}

The eight parent strains that were selected based on prescreenings were transformed with CRISPR/Cas9 plasmids containing protospacer sequences targeting either MATa or MAT $\alpha$ using optimized stationary phase transformation (Tripp et al. 2013). Transformation efficiencies varied broadly, with between 1 and 133 colonies emerging on the selection plates (400 $\mathrm{mg}$ hygromycin $/ \mathrm{mL}$ ) from the transformation of $1.5 \mathrm{~mL}$ saturated overnight culture (Table 1). Colonies were obtained for all 16 combinations (eight strains with two plasmids). Up to six colonies from each strain and plasmid were transferred to fresh selection plates, after

Table 1 Colonies appearing on selection plates after transformation by Cas 9 plasmid targeting MATa or MAT $\alpha$

\begin{tabular}{llll}
\hline Strain number & Strain name & MATa plasmid & MAT $\alpha$ plasmid \\
\hline 4 & Ardennes & 11 & 18 \\
5 & Classic Wit & 5 & 5 \\
10 & St Lucifer & 4 & 7 \\
17 & Foggy & 4 & 1 \\
21 & Sterling & 28 & 10 \\
26 & Ebbegarden & 8 & 13 \\
36 & Cerberus & 4 & 3 \\
41 & YJM1400 & 63 & 133 \\
\hline
\end{tabular}

which DNA was extracted and PCR was used to confirm successful mating-type change (Supplementary Fig. S2). Out of the 80 colonies that were tested, mating-type change

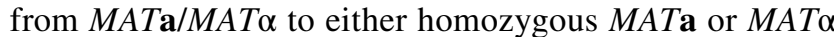
had successfully occurred in 73 .

Next, these 73 transformants were streaked for single colonies two successive times on non-selective media (YPD without hygromycin) to encourage loss of the CRISPR/Cas9 plasmid. Plasmid loss was confirmed in 66 transformants by lack of growth when transferred back to selection plates. As all eight parent strains are homothallic, we were unsure if the mating type would remain stable after loss of the CRISPR/Cas9 plasmid. In wild-type homothallic strains, mating-type change would occur at cell division following the repair of a double-stranded break (DSB) created by the $\mathrm{HO}$ endonuclease at the mating-type locus. We retested the mating type of all 66 transformants lacking the CRISPR/ Cas9 plasmid by PCR, and all strains still exhibited a single mating type. Stable homozygous MATa and MAT $\alpha$ variants were successfully obtained for all eight parent strains. The CRISPR-based mating-type switching process developed by Xie et al. (2018) therefore appears to generate stable matingcompetent variants even from homothallic industrial strains.

As the protospacer sequences used to target MATa and $M A T \alpha$ are also present in the silent mating-type cassettes $H M R \mathbf{a}$ and $H M L \alpha$ on either end of chromosome III, we hypothesized that the stable mating type in the transformed homothallic strains are a result of simultaneous conversion of the respective silent mating-type cassettes. To test this, we performed PCR on wild-type and transformed strains using primers designed to amplify $H M R \mathbf{a}$ and $H M L \alpha$. Wildtype strains yielded products with both primer pairs, while transformants only yielded single products, indicating that $H M R \mathbf{a}$ and $H M L \alpha$ were indeed converted or deleted during the mating-type switching process (Supplementary Fig. S3).

\section{Construction of hybrids}

Following the successful isolation of stable mating-competent variants of the eight selected parent strains, we proceeded with hybridization attempts (Fig. 2A). From these strains, we attempted 21 crosses in total. As the end goal was to obtain a yeast strain lacking the POF phenotype, each cross involved at least one POF- parent. Hybridizations were attempted by placing cells of both parent strains adjacent to one another on a YPD agar plate using a Singer MSM400 dissection microscope. Sixteen pairs per cross were placed together. Of the 21 attempted crosses, 18 successfully yielded hybrids (for a total of 63 hybrids; Supplementary Table S3). Successful hybrids were named based on the strain codes of the parent strains (e.g. $21 \times 10$ ) followed by a unique alphanumeric code (e.g. D4). Hybridization frequency (i.e. confirmed hybrids out of 16 attempts) varied 


\section{A}

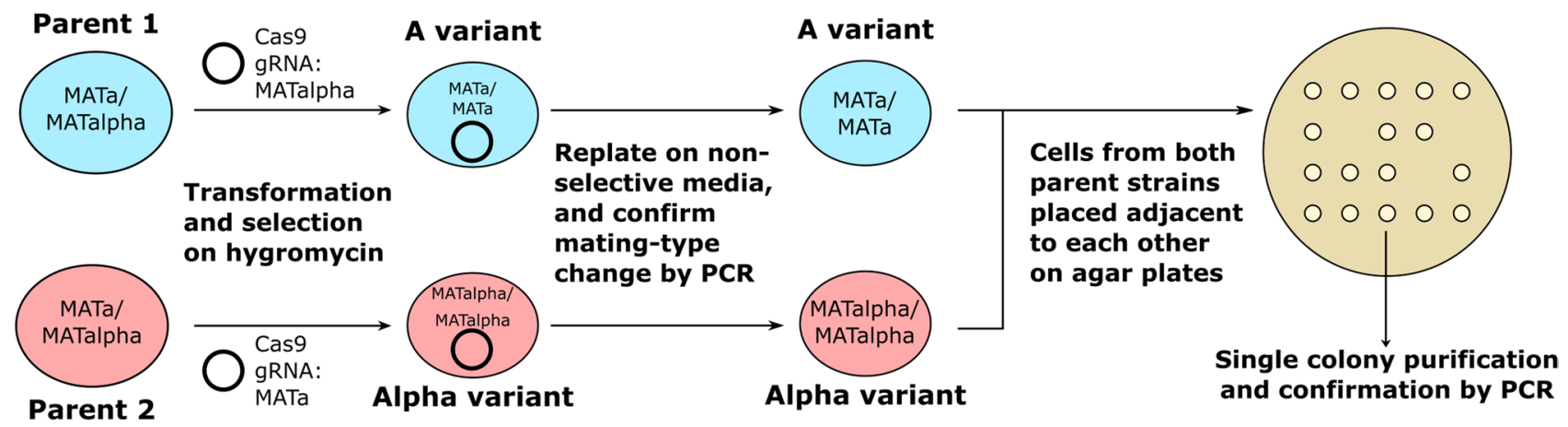

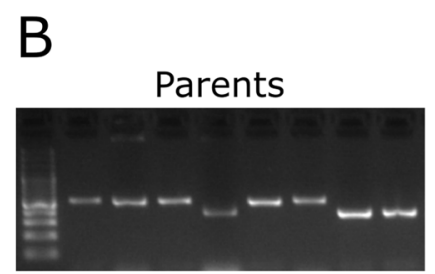

Hybrids

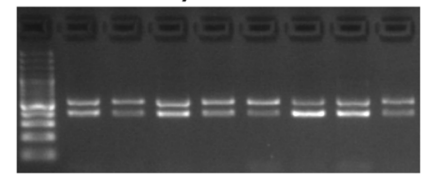

Primer pair: MAT-R - MATalpha - MATa
C

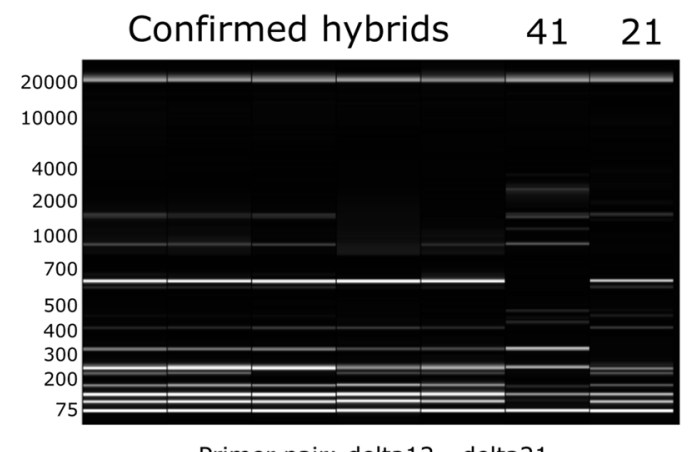

Primer pair: delta12 - delta21

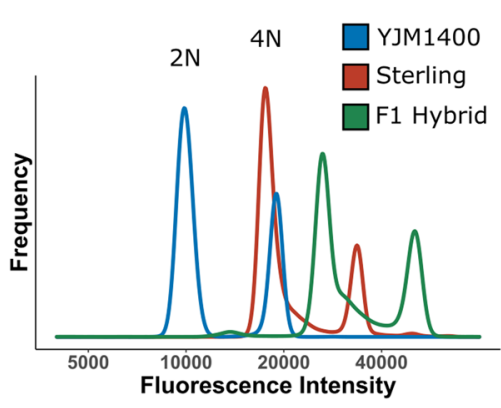

Fig. 2 Overview of hybrid construction and confirmation. A Scheme of how parent strains were converted to mating-competent variants, which were then mated to form hybrids. B Mating-type PCR to confirm hybridization. Parents produced a single band for either MATa or $M A T \alpha$, while hybrids produced both bands. C Interdelta fingerprints

considerably between the successful crosses, ranging from 6.3 to $63 \%$ (median $18.8 \%$, average $25 \%$ ). Hybridization was confirmed by checking both for heterozygosity at the MAT locus using PCR (as both parent strains showed stable single mating types) and by producing interdelta fingerprints using PCR and capillary electrophoresis (examples in Fig. 2B and $\mathrm{C}$ ). In the interdelta fingerprints, successful hybrids produced bands of both parent strains. Flow cytometry and DNA staining with SYTOX Green of selected hybrids also revealed that ploidy of the hybrid strains had increased to levels above both parent strains (Table 2). Crossing of the tetraploid strain 21 (Sterling) and diploid strain 41 (YJM1400), for example, resulted in a hexaploid hybrid (Fig. 2D). Indeed, of the seven hybrids of which the ploidy was measured, six appeared to be approximately hexaploid.

After hybrids were successfully constructed and confirmed, we still attempted to remove the POF phenotype from hybrid combinations involving a $\mathrm{POF}+$ parent strain through meiotic segregation. Hybrids from five crosses involving a POF + parent strain (indicated by asterisks in Table 2) were spread on potassium acetate agar for to confirm hybridization. Hybrids produce fingerprints containing all the bands of the parent strains. D Flow cytometry and SYTOX Green staining reveal an increased ploidy of the F1 hybrid formed between Sterling and YJM1400 compared to the parent strains

sporulation. Prior to sporulation, all successful hybrids from these crosses were screened for $\beta$-lyase activity by testing growth on cysteine as the sole nitrogen source. The best performing hybrid from each cross was chosen for sporulation. All five hybrids sporulated efficiently and formed viable spores, with spore viability ranging from 39 to $69 \%$. A total of 47 spore clones were obtained. Spore clones were named based on the strain code of the hybrid from which they were derived (e.g. $21 \times 10$ D4) followed by an additional unique alphanumeric code (e.g. C3). The ploidy of selected spore clones was measured with flow cytometry, and it had halved compared to the F1 hybrid in most cases (Table 2). We were unable to sporulate those hybrids that were created between two 'Beer 1'/ 'Ale beer' strains, likely as a result of both parent strains being sterile.

\section{Screening of constructed hybrids reveals heterosis}

The spore clones, along with selected F1 hybrids and parent strains were first screened for various relevant traits in microplate format. These included efficient fermentation of 
Table 2 Estimated ploidy of selected parent strains, hybrids and spore clones as measured by SYTOX Green staining and flow cytometry. F1 hybrids marked with an asterisk $(*)$ were sporulated

\begin{tabular}{lll}
\hline Strain & Type & Ploidy \\
\hline St. Lucifer (10) & Parent strain & $1.9 \pm 0.09$ \\
Foggy (17) & Parent strain & $4.1 \pm 2.64$ \\
Sterling (21) & Parent strain & $3.8 \pm 0.18$ \\
Ebbegarden (26) & Parent strain & $3.9 \pm 0.13$ \\
Cerberus (36) & Parent strain & $2.0 \pm 0.14$ \\
YJM1400 (41) & Parent strain & $2.1 \pm 0.11$ \\
$21 \times 10$ D4 $*$ & F1 hybrid & $6.0 \pm 0.86$ \\
$21 \times 41$ A2 $*$ & F1 hybrid & $6.0 \pm 1.29$ \\
$26 \times 10$ D1 $*$ & F1 hybrid & $5.5 \pm 0.49$ \\
$26 \times 17$ D3 & F1 hybrid & $5.7 \pm 1.12$ \\
$26 \times 41$ A3 $*$ & F1 hybrid & $5.9 \pm 0.74$ \\
$36 \times 26$ D3 & F1 hybrid & $5.9 \pm 0.93$ \\
$36 \times 41$ A2 $*$ & F1 hybrid & $4.0 \pm 0.16$ \\
$21 \times 10$ D4 C3 & F1 spore clone & $2.8 \pm 0.13$ \\
$21 \times 41$ A2 A3 & F1 spore clone & $2.8 \pm 0.11$ \\
$21 \times 41$ A2 B3 & F1 spore clone & $3.4 \pm 0.65$ \\
$21 \times 41$ A2 D1 & F1 spore clone & $2.9 \pm 0.16$ \\
$21 \times 41$ A2 E1 & F1 spore clone & $2.6 \pm 0.12$ \\
$26 \times 10$ D1 A2 & F1 spore clone & $5.0 \pm 0.84$ \\
$26 \times 41$ A3 B3 & F1 spore clone & $3.0 \pm 0.21$ \\
$36 \times 41$ A2 A3 & F1 spore clone & $2.1 \pm 0.17$ \\
\hline & &
\end{tabular}

wort, lack of phenolic off-flavour production, and ability to grow on cysteine as a sole nitrogen source (as an indicator of $\beta$-lyase activity). Considerable variation was observed among the screened traits in the 60 strains (Supplementary Fig. S4). We decided to focus on the Sterling $\times$ YJM1400 hybrid $(21 \times 41$ A2) and derived spore clones in more detail. In regard to the ability to grow on and consume $15 \mathrm{mM}$ cysteine as a sole nitrogen source, we observed mid-parent heterosis in the F1 hybrid and derived spore clones (Fig. $3 \mathrm{~A}$ and B). Numerous spore clones outperformed the F1 hybrid. We also measured IRC7 copy number (normalized to the copy numbers of $A L G 9$ and $U B C 6$ that were chosen as reference genes) by quantitative PCR and observed a moderately strong positive correlation between IRC7 copy numbers and the measured phenotypes (Fig. $3 \mathrm{C}$ and D).

The F1 hybrid and spore clones, along with the ale parent Sterling, fermented the $15^{\circ}$ Plato wort efficiently, with measured ethanol levels ranging from around 50 to $60 \mathrm{~g} / \mathrm{L}$ (corresponding to approximately $6.2-7.5 \%$ alcohol by volume) (Fig. 3E). The wild parent YJM1400 only reached $20 \mathrm{~g}$ ethanol/L, indicating it was unable to ferment maltose and maltotriose from the wort. Strains were grown in the presence of ferulic acid to test phenolic off-flavour (POF) formation. As expected, the greatest conversion of ferulic acid to 4-vinylguaiacol was observed for the wild parent YJM1400 as indicated by the greatest drop in absorbance at $320 \mathrm{~nm}$ (Fig. 3F). Interestingly, barely any drop in absorbance was observed with the F1 hybrid, despite it containing functional alleles of $P A D 1$ and $F D C 1$ from YJM1400. Similarly to the other traits, considerable variation was observed among the spore clones. $P A D 1$ and $F D C l$ were Sanger-sequenced in the fourteen strains (two parents, one F1 hybrid, and eleven spore clones) to clarify the results of the POF assay (Supplementary Fig. S5). Homozygous loss-of-function (LOF) mutations in $P A D 1$ and $F D C l$ were observed in the ale parent Sterling, as well as two out of eleven spore clones (A2 $\mathrm{B} 2$ and A2 C4). This ratio (0.18) corresponds well to the predicted ratio of spore clones being homozygous for the LOF mutations, assuming the spore clones are triploid and the hexaploid hybrid has four LOF alleles and two functional alleles $(C(4,3) / C(6,3)=0.2)$.

After high-throughput screening, a total of seven hybrids and eight spore clones, along with the six parent strains, were selected for $400 \mathrm{~mL}$-scale wort fermentations (Fig. 4A and Supplementary Fig. S6). Best-parent heterosis was observed in regard to fermentation rate, as F1 hybrids reached the mid-point of fermentation significantly faster than the parent strains (Fig. 4B). F1 hybrids also reached, on average, a higher attenuation level, but the difference to the parent strains was not significant (Fig. 4C). The spore clones appeared to perform on average slightly worse than the F1 hybrids in regard to fermentation rate and final attenuation; however, the difference was not significant $(p>0.05)$.

\section{Confirmation of enhanced phenotype in 2L-scale wort fermentations}

Two F1 hybrids and two derived spore clones were selected for 2L-scale wort fermentations and more detailed phenotyping. Both hybrids involved the wild parent YJM1400, with the other parent being one of two brewing strains, Sterling or Ebbegarden. As was already observed during the smaller scale wort fermentations, the F1 hybrids exhibited best-parent heterosis in regard to fermentation rate (Fig. 5A). The Sterling $\times$ YJM1400 hybrid $21 \times 41$ A2, for example, had reached $3.9 \% \mathrm{ABV}$ (alcohol by volume) after $23 \mathrm{~h}$ compared to $2.4 \%$ in Sterling $(p=0.001)$. The wild parent YJM1400 was unable to utilize the maltose and maltotriose in the wort and only reached $1.4 \% \mathrm{ABV}$. The fermentation profile of the Sterling $\times$ YJM1400 spore clone $21 \times 41$ A2 E1 was identical to the Sterling parent, while the Ebbegarden $\times$ YJM1400 spore clone $26 \times 41$ A3 B3 fermented slower than the F1 hybrid or ale parent.

The concentrations of 4MMP and 3MHA in the finished beers were also measured (Fig. 5B and C). A significant increase in 4MMP was observed for the Sterling $\times$ YJM1400 hybrid $21 \times 41$ A2 compared to the parent strains $(p<0.05)$, while significant increases in 3MHA were observed for both 
A Growth on $15 \mathrm{mM}$ cysteine

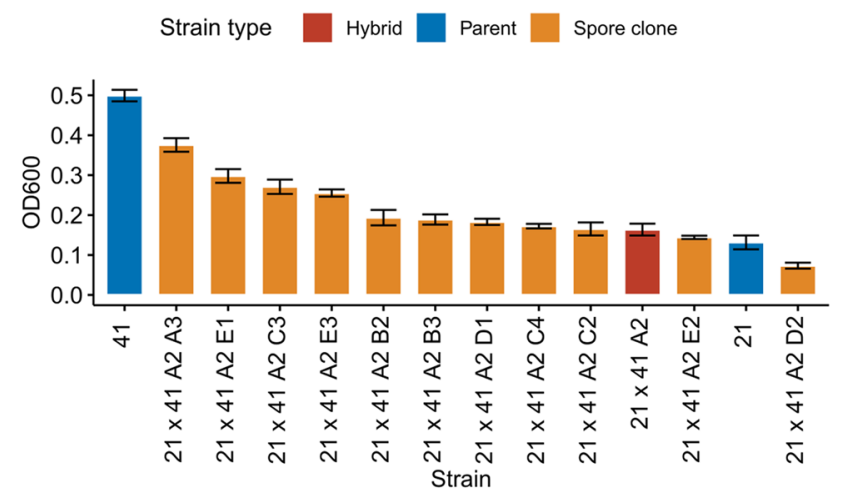

$\mathrm{C}$

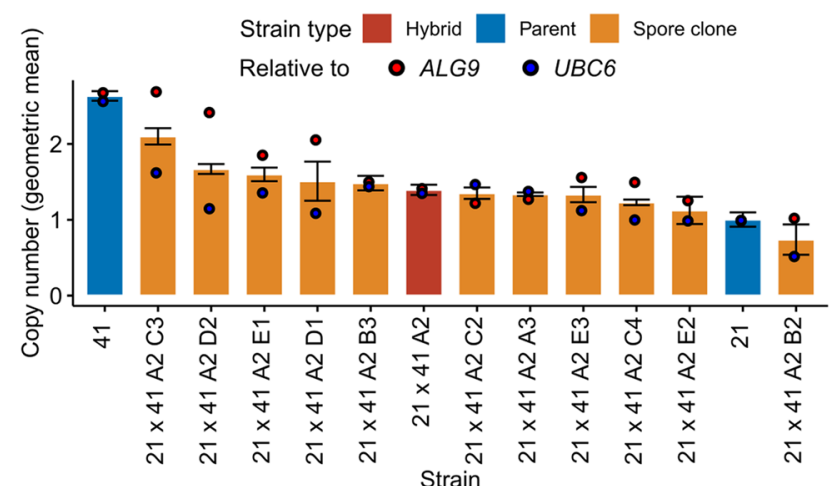

$E$

E Ethanol formation in wort

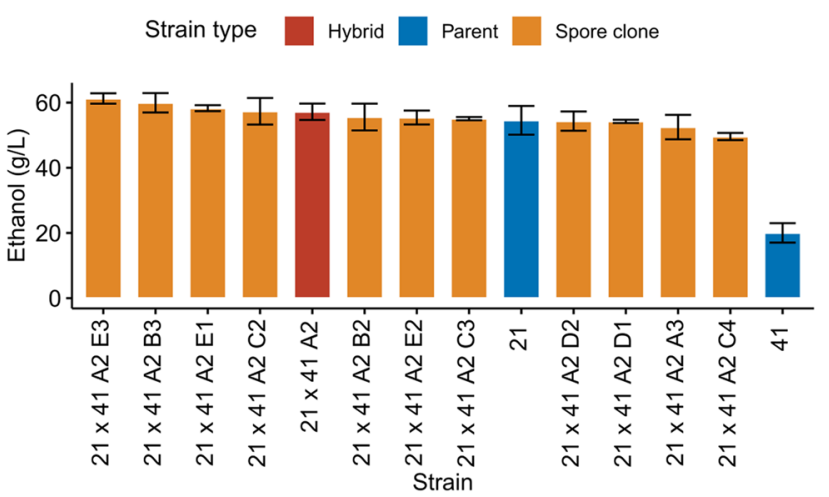

Fig. 3 Phenotypic screening of Sterling $\times$ YJM1400 hybrid and eleven spore clones. A The OD600 reached when grown on $15 \mathrm{mM}$ cysteine as sole nitrogen source. B The amount of cysteine consumed during the cultivations on $15 \mathrm{mM}$ cysteine as sole nitrogen source. C The relative $I R C 7$ copy number normalized to $A L G 9$ and $U B C 6$, as determined by quantitative PCR. D The correlation between IRC7 copy number and growth on $15 \mathrm{mM}$ cysteine as sole nitrogen source.

the F1 hybrids. No significant differences in 3MH concentrations were observed between the hybrids and the best parents (data not shown). Concentrations of both 4MMP and 3MHA were above or around the flavour threshold ( 1 and $4 \mathrm{ng} / \mathrm{L}$,
B Cysteine consumed on $15 \mathrm{mM}$ cysteine

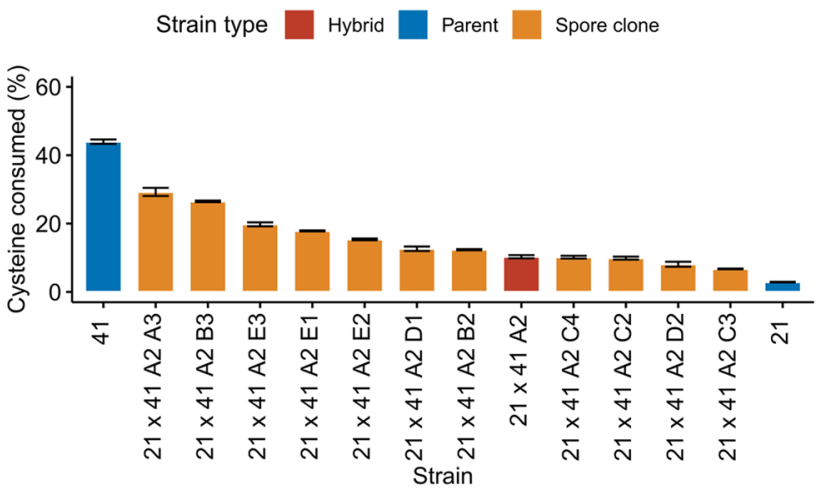

D
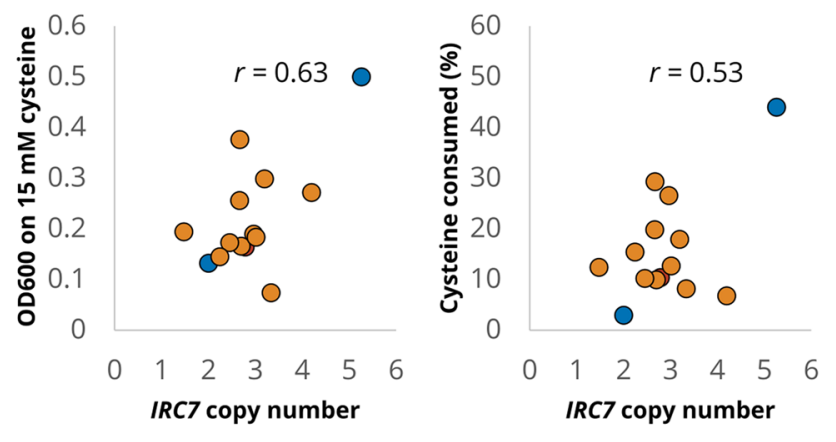

$\mathrm{F}$

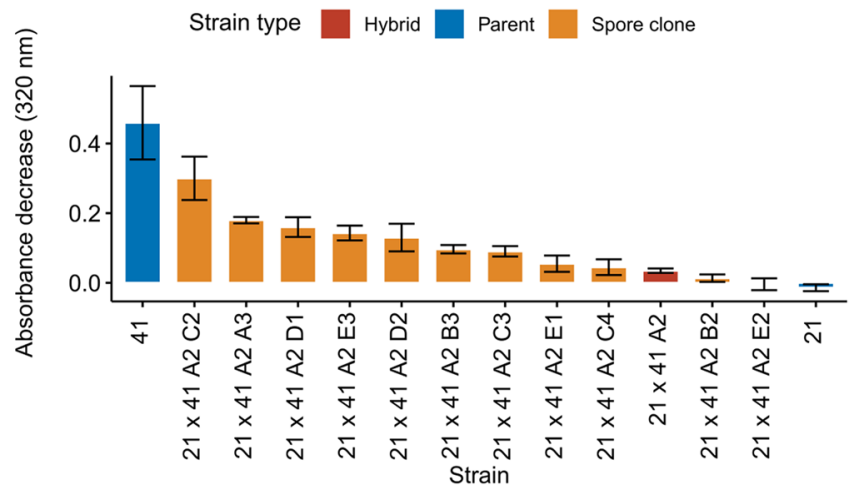

E The amount of ethanol (g/L) produced from $15^{\circ} \mathrm{P}$ wort in microplate fermentations. F The decrease in absorbance at $320 \mathrm{~nm}$ after cultivations in $100 \mathrm{mg} / \mathrm{L}$ ferulic acid. A larger decrease in absorbance indicates more conversion of ferulic acid to 4-vinylguaiacol. Assays were done in triplicate, and error bars represent standard deviation. 21: Sterling. 41: YJM1400

respectively (Capone et al. 2018)) in the beers fermented with the hybrid strains, indicating a positive influence on flavour. Interestingly, despite the high apparent $\beta$-lyase activity in the YJM1400 strain, the beers made with this strain 


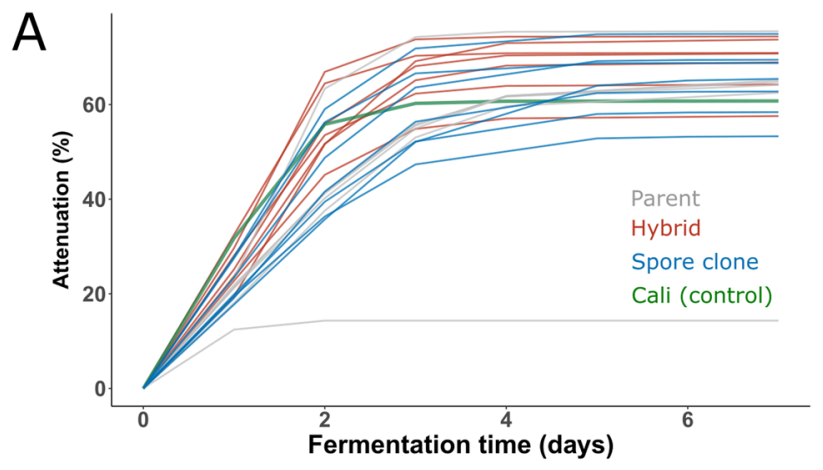

beers fermented with the POF- parent strains (Sterling and Ebbegarden). Concentrations of yeast-derived esters were also enhanced in several of the beers produced with the hybrid strains (Fig. 6A to C). The Ebbegarden $\times$ YJM1400 spore clone $26 \times 41$ A3 B3, in particular, produced higher levels of 3-methylbutyl acetate, ethyl hexanoate, and ethyl octanoate compared to either parent. We also measured the flocculation potential of the strains (a desirable trait in brewing strains), and it remained as high as in the ale parent for three out of the four hybrid strains (Fig. 6D).

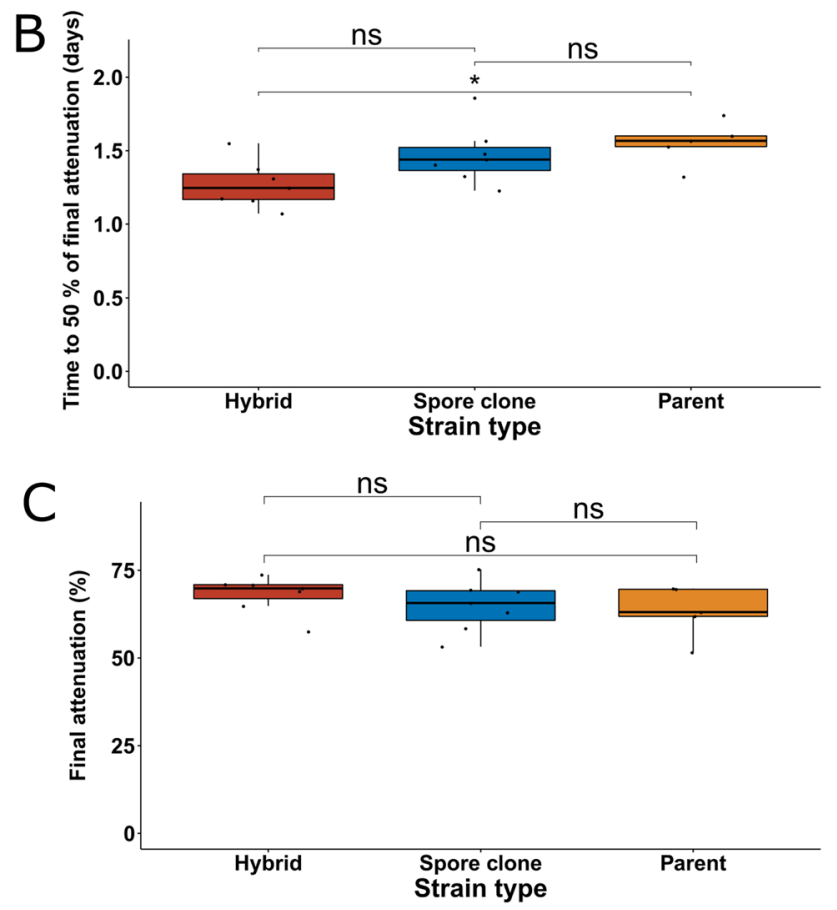

\section{Whole genome sequencing of the selected hybrid strains}

The four hybrid strains that were studied in more detail above were whole genome sequenced. The F1 hybrids were nearly euploid, having six copies of almost all chromosomes (Fig. 7A). The spore clones had more variation in chromosome copy numbers, ranging from two to four. The F1 hybrids had high levels of heterozygosity, as over $100 \mathrm{k}$ heterozygous variants were identified in both hybrids (Fig. 7B). Loss of heterozygosity (LOH) had occurred in the $\mathrm{F} 1$ spore clones, as the number of heterozygous variants decreased with approx. $20 \%$. When the parent strains were compared to each other, a total of 50,385 and 36,642 variants unique to each parent were identified when Sterling and YJM1400 were compared, respectively. When Ebbegarden and YJM1400 were compared, 48,157 and 32,509 variants unique to each parent were identified, respectively. $\mathrm{LOH}$ had occurred for 1222 and 326 of the variants unique to Sterling and YJM1400, respectively, in the Sterling $\times$ YJM1400 spore clone $21 \times 41$ A2 E1, as they were now homozygous (Fig. 7 $\mathrm{B}$ and C). Similarly, 1038 and 1194 of the variants unique to Ebbegarden and YJM1400, respectively, were now homozygous in the Ebbegarden $\times$ YJM1400 spore clone $26 \times 41$ A3 B3. When plotted along the genome, these parent-specific homozygous sites were spread across the whole genome (Fig. 7C).

In regard to the $\beta$-lyase encoding IRC7 gene, we saw both differential distribution of inactivating mutations and gene copy numbers among the parent and hybrid strains (Fig. 7 D and E). The Sterling parent strain contained three inactivating mutations with $50 \%$ allele frequency. These mutations were detected in the derived hybrids but at a lower allele frequency (Fig. 7D). None of the known inactivating mutations in IRC7 (Fig. 1) were observed in the Ebbegarden and YJM1400 parent strains, nor in their derived hybrids. IRC7 copy numbers in the strains were estimated based on median coverage across the gene, normalized to the coverage across chromosome VI on which it is located. The copy numbers were as expected highest in the F1 hybrids but decreased in the spore clones (Fig. 7E). Nevertheless, IRC7 copy numbers in the spore clones appeared higher than in the respective ale parent from 
Fig. 5 Fermentation performance and concentrations of thiols and 4-vinylguaicol in $2 \mathrm{~L}$-scale fermentations. A Alcohol by volume (\%) during fermentations. Concentrations (ng/L) of B 4-mercapto4-methyl-2-pentanone (4MMP) and C 3-mercaptohexylacetate (3MHA) in the beers. An asterisk (*) indicates a concentration significantly higher $(p<0.05)$ than both parent strains as determined by unpaired twotailed $t$-test. D Concentrations of 4-vinylguaicol $(\mathrm{mg} / \mathrm{L})$ in the beers. Different letters indicate significant differences $(p<0.05)$ as determined by one-way ANOVA and Tukey's posthoc test. Fermentations were performed in triplicate

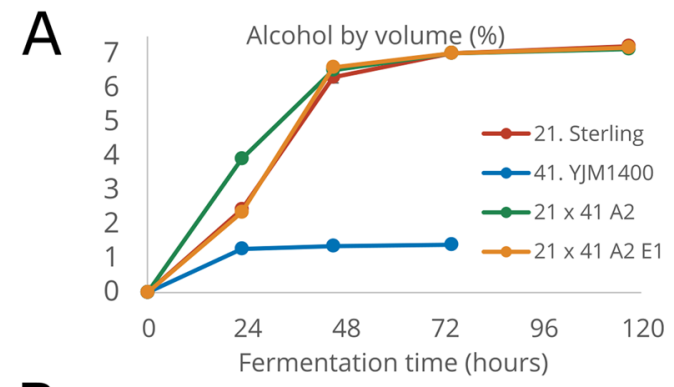

B
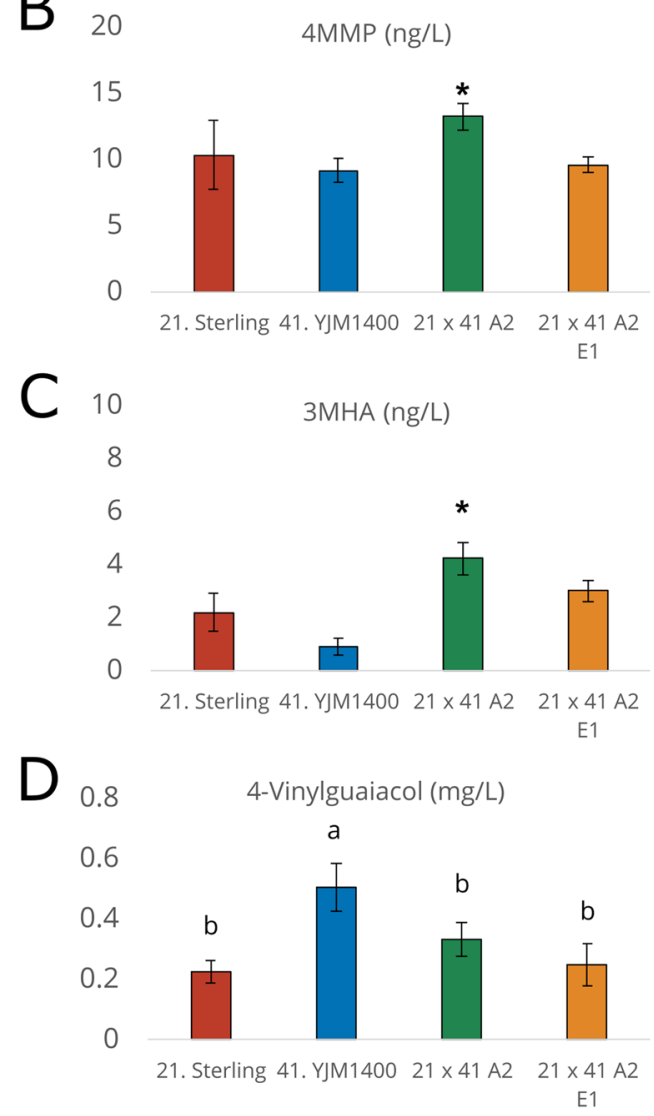

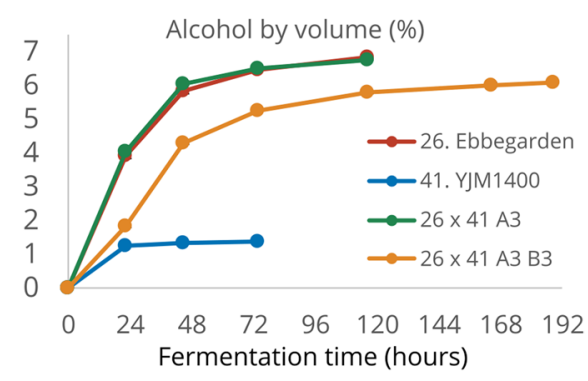

$20 \quad 4 M M P(n g / L)$
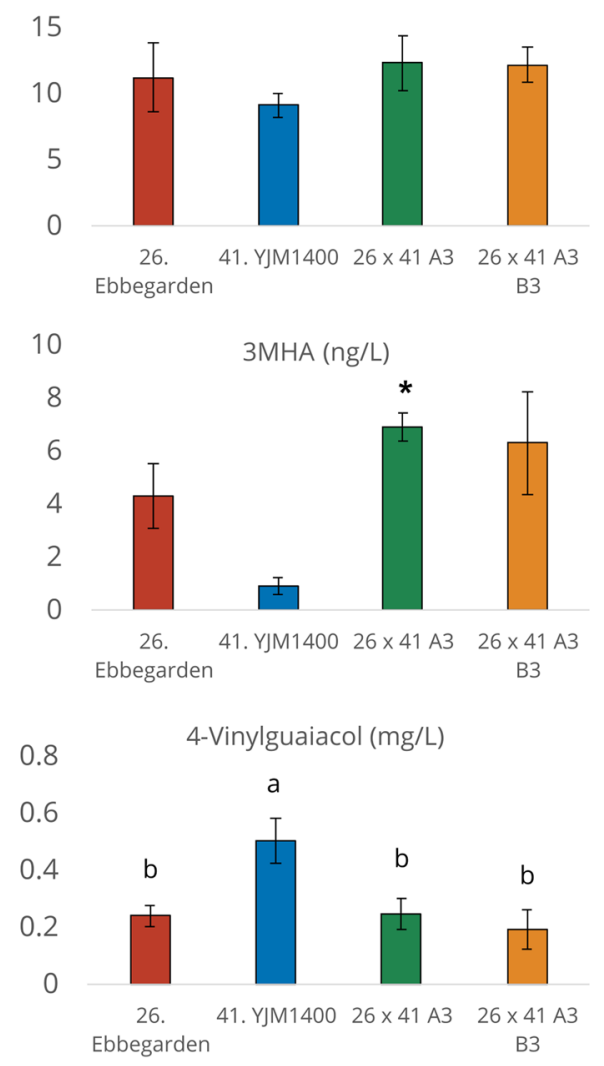

which they were derived. A moderate positive correlation ( $r=0.65$ ) was observed between IRC7 copy numbers and amount of 4MMP in the beers fermented with the strains. The heterozygous nonsense mutation in URE2, present in Sterling with an allele frequency of $25 \%$, was expectedly detected in only one of six URE2 alleles in the Sterling $\times$ YJM1400 hybrid $21 \times 41$ A2 and is therefore unlikely to have had a considerable impact on IRC7 expression. The mutation was not detected in the derived spore clone $21 \times 41$ A2 E1.

\section{Discussion}

Breeding with brewing yeast can be challenging, as most strains sporulate poorly or are unable to form viable spores (Gallone et al. 2016; De Chiara et al. 2020). Such strains can be bred with 'rare mating' (Gunge and Nakatomi 1972), but the approach is time-consuming and often not successful. Here, we set out to evaluate whether breeding of sterile industrial strains can be facilitated using CRISPR/Cas9aided mating-type switching (Xie et al. 2018). Our results reveal that single mating-type variants of industrial polyploid strains can indeed be readily generated and isolated. Interestingly, the mating type remained stable even after loss of the Cas 9 plasmid, despite the strains being homothallic. Wild-type homothallic strains would, by action of the $\mathrm{HO}$-coded endonuclease, switch mating type at cell division and subsequently self-mate to reform a cell heterozygous at the mating-type locus (Merlini et al. 2013). Here, no such mating-type switching was observed, likely from the simultaneous conversion or loss of the silent mating-type cassettes during the Cas 9 transformations. This allows for the easy 
Fig. 6 Ester concentrations and flocculation potential in $2 \mathrm{~L}$-scale fermentations. Concentrations $(\mathrm{mg} / \mathrm{L})$ of A 3-methylbutyl acetate, B ethyl hexanoate, and $\mathbf{C}$ ethyl octanoate in the beers. D Flocculation potential as determined by Helm's test. Different letters indicate significant differences $(p<0.05)$ as determined by one-way ANOVA and Tukey's post-hoc test. Fermentations were performed in triplicate

\section{A} 3-Methylbutyl acetate (mg/L)

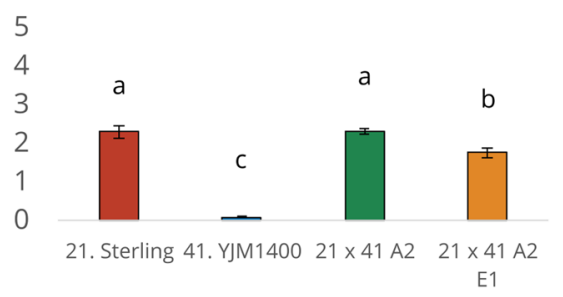

B
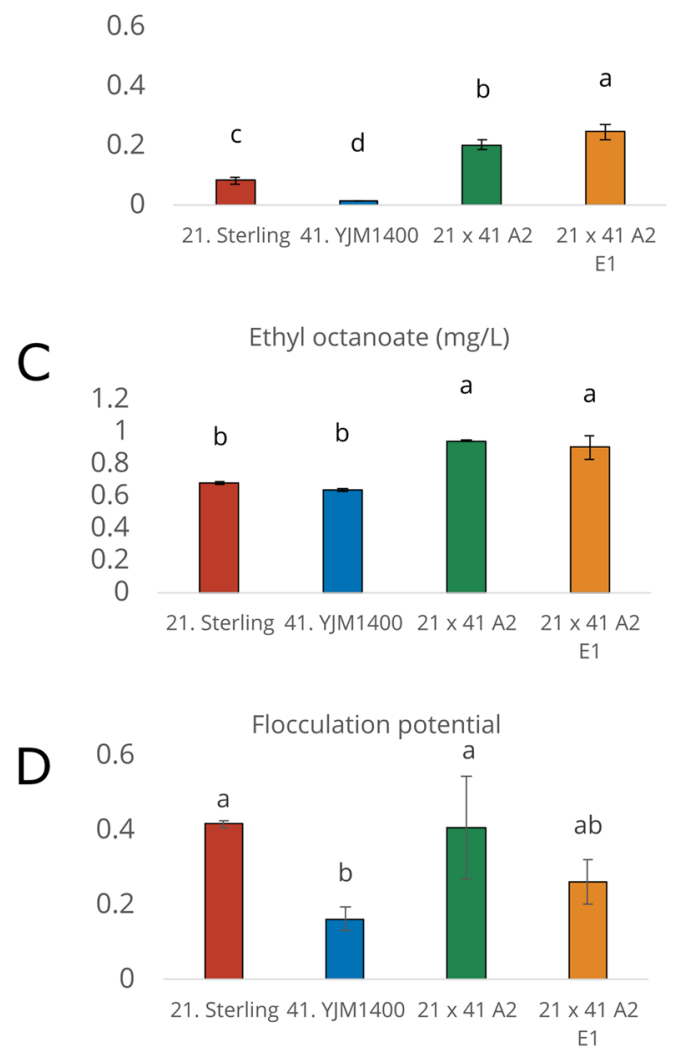

3-Methylbutyl acetate ( $\mathrm{mg} / \mathrm{L})$

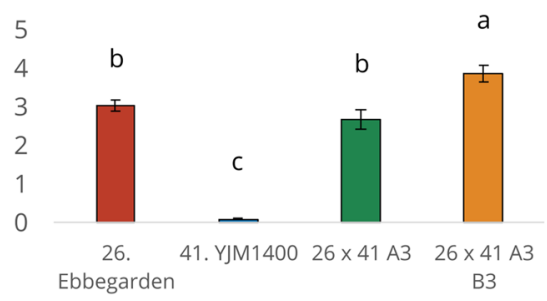

Ethyl hexanoate (mg/L)

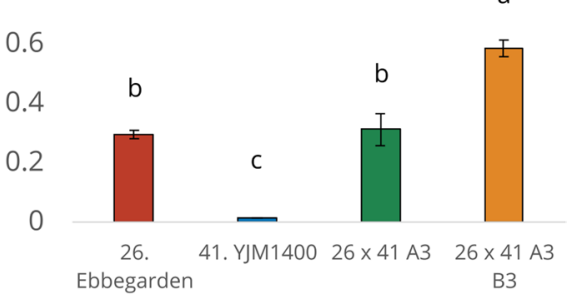

Ethyl octanoate (mg/L)
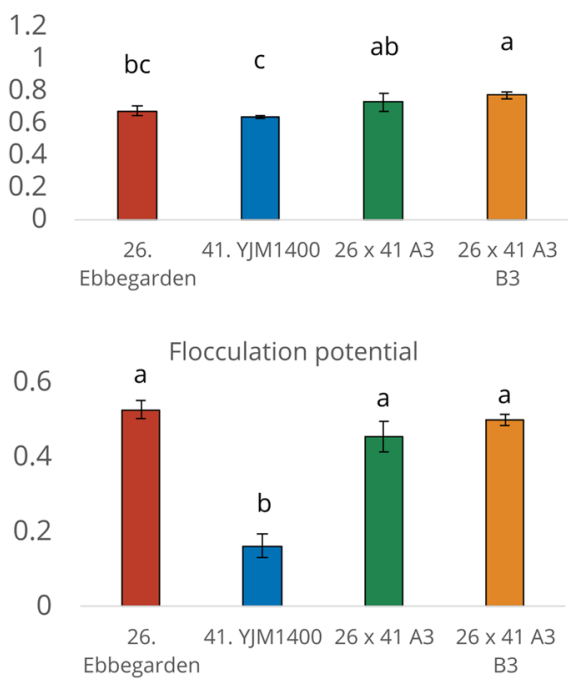

construction and maintenance of a library of mating-competent variants for large-scale breeding projects. Furthermore, while the sterility of the 'Beer 1'/'Ale beer' strains prevents using meiotic segregation to generate phenotypic diversity, we could here diversify the hybrids that were produced between sterile 'Beer 1'/'Ale beer' strains and a fertile strain (e.g. St. Lucifer, Cerberus and YJM1400) through sporulation. Expectedly, the hybrids that we constructed between two sterile 'Beer 1'/'Ale beer' strains remained sterile. It has been proposed that the sterility in these strains is due to chromosomal aneuploidy (De Chiara et al. 2020); however, it is unclear why fertility was rescued here when crossed with a fertile diploid strain.

The single mating-type variants readily mated with cells of opposite mating type, which allowed rapid construction of a large set of intraspecific hybrids. Numerous studies have demonstrated how breeding can be used to combine and enhance traits from diverse strains (Steensels et al. 2014; Krogerus et al. 2015, 2016; Mertens et al. 2015). Hence, the approach used here can accelerate and simplify brewing yeast development through breeding, where hybrid construction would otherwise typically be the bottleneck. Here, we also observed heterosis for a number of traits in multiple hybrids, including fermentation rate and aroma formation. While not tested here, it is likely that the same approach, following modification of the protospacer sequences, could be applied to other Saccharomyces species as well to allow construction of interspecific hybrids. Furthermore, hybrids could also likely be retransformed to form mating-competent cells that could be bred with another parent strain. This would allow construction of multi-parent complex hybrids, such as those described by Peris et al. (2020). 
Fig. 7 Whole genome sequencing of selected hybrids and spore clones. A The estimated chromosome copy number and measured ploidy of the parent strains, hybrids, and spore clones. B The amount of heterozygous and homozygous variants (compared to the $S$. cerevisiae S288C reference genome) detected in the strains. C Loss-of-heterozygosity regions where parent-specific mutations were homozygous in the spore clones (mutations were all heterozygous in the F1 hybrids). D Allele frequencies of the IRC7 mutations in the Sterling $\times$ YJM1400 strains. E The estimated copy number of $I R C 7$ in the strains and correlation with beer 4MMP concentrations. Copy number was estimated based on median read coverage across $I R C 7$, normalized to the read coverage across chromosome VI where the gene is located
A

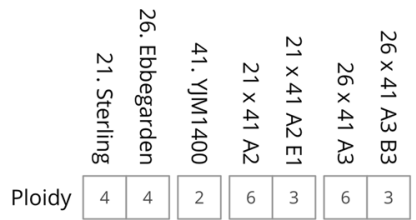

B

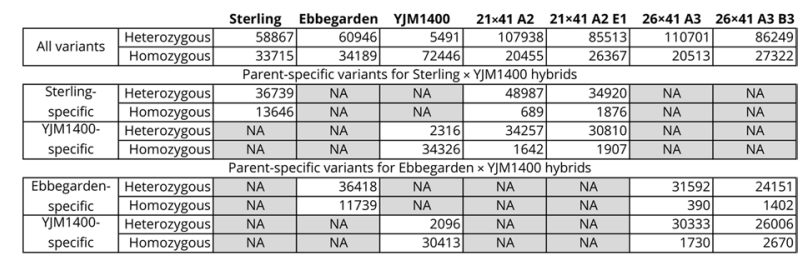

C $21 \times 41$ A2 E1

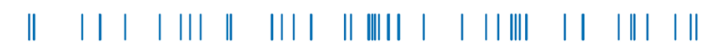

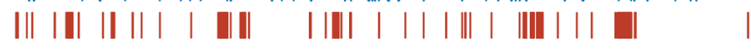

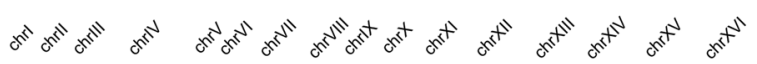
$26 \times 41$ A3 B3

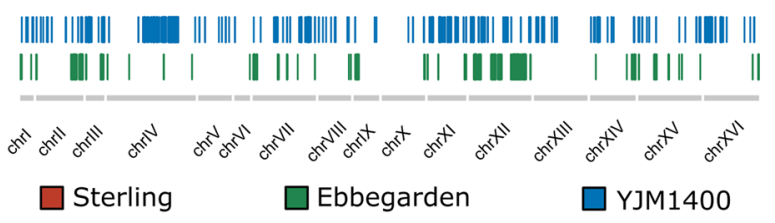

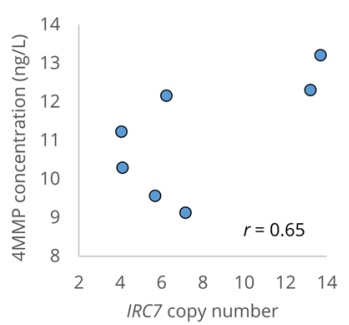

Here, we aimed specifically at enhancing the $\beta$-lyase of selected brewing yeast strains. Volatile thiols have a central role in contributing fruity hop aroma in beer, and they typically are abundant in modern heavily hopped IPA-style beers (Gros et al. 2012; Cibaka et al. 2017; Dennenlöhr et al. 2020; Bonnaffoux et al. 2021). As the vast majority of all thiols in hops are cysteine- or glutathione-conjugated and therefore odourless, there exists a large potential pool of aroma that can be freed from $\beta$-lyase activity, such as by Irc7p (Roncoroni et al. 2011; Roland et al. 2016). Here, we observed a variable distribution of inactivating mutations in $I R C 7$ among the screened brewing strains and hybrids, as well as $I R C 7$ copy number variations between parents, hybrids, and spore clones. These mutations have been demonstrated to directly influence wine thiol levels (Cordente et al. 2019). However, we only observed a minor, but positive, effect on beer thiol levels. Additionally, differences were only observed for concentrations of 4MMP and 3MHA, not $3 \mathrm{MH}$, despite hops containing a significantly larger pool of $3 \mathrm{MH}$ precursors compared to 4MMP precursors (Gros et al. 2012; Roland et al. 2016). This could be explained by activity of other $\beta$-lyase enzymes (e.g. those coded by STR3 and CYS3; Cordente et al. 2019). A similar observation regarding lack of correlation between IRC7 mutations and beer thiols levels was found in a recent study (Michel et al. 2019). It is possible that beer environment is not optimal for $\beta$-lyase activity, but that requires further clarification. Indeed, a recent study showed variation in amount of thiols released from supplemented glutathionylated and cysteinylated forms based on wort extract levels and fermentation temperature, but maximum release ratio for the bound forms remained below $0.5 \%$ and $0.1 \%$, respectively (Chenot et al. 2021). Nevertheless, we succeeded in our goal of enhancing thiol release through breeding. Beer yeasts with enhanced $\beta$-lyase activity could help brewers heighten the flavour of popular beer styles such as "hazy" IPA and/or reduce the cost impact of modern IPA hopping rates.

The use of genetically modified yeast for beverage production is still prohibited in most parts of the world, and the hybrid strains generated are considered genetically 
modified (Alperstein et al. 2020). However, the strains can be considered cisgenic or self-cloned, as no exogenous DNA is present in the cells and the Cas9 enzyme has only been used to create a DSB in the mating-type locus (similarly to HO endonuclease). Hence, the strains are currently suitable for certain markets, including North America and Japan (Fischer et al. 2013). Regarding industrial suitability of the hybrids, previous yeast breeding studies have revealed that hybrid genomes may be unstable, and they can undergo substantial structural changes when repeatedly grown in a wort environment (Pérez-Través et al. 2014; Mertens et al. 2015; Krogerus et al. 2018). It is therefore vital that the long-term stability of the hybrids generated here is studied, through testing performance in beer fermentation and reuse over multiple yeast pitch generations. This is particularly important as polyploid strains have been shown to undergo chromosome losses during stress adaptation (Selmecki et al. 2015; Scott et al. 2017; Krogerus et al. 2018). In addition, CRISPR/Cas9-editing may result in unwanted off-target mutations and large-scale structural variations in heterozygous yeast strains (Mertens et al. 2019; Gorter de Vries et al. 2019). While not studied here, it would be crucial to investigate whether the CRISPR-mediated mating-type switching can cause unwanted off-target mutations in the strains. Furthermore, suitability of these strains in combination with different hop varieties for production of aroma-forward beers has not yet been explored and may yield further insight into the aroma-enhancing potential of these yeasts.

In conclusion, our study confirms that CRISPR/Cas9aided mating-type switching can be applied to homothallic aneuploid industrial yeast strains, and the switched strains can be readily mated to form hybrids. This allows for the rapid breeding of brewing strains and overcomes the bottleneck caused by their sterility and polyploidy. The brewing hybrids constructed here exhibited heterosis across a variety of traits, including fermentation performance and aroma formation. Our results corroborate previous research highlighting the power of yeast breeding for strain development.

Supplementary Information The online version contains supplementary material available at https://doi.org/10.1007/s00253-021-11626-y.

Acknowledgements We thank Aila Siltala, Niklas Fred, Eero Mattila, and Ronja Eerikäinen for technical assistance, Dominik Mojzita for preparing the Cas9 plasmids, and George van der Merwe for sharing genome sequencing data.

Author contribution KK: Conceived the study, designed experiments, performed experiments, analysed all data, wrote the manuscript.

EF: Designed experiments, performed $400 \mathrm{~mL}$ wort fermentations, edited the manuscript.

NR: Performed thiol analysis, edited the manuscript.

BG: Conceived the study, designed experiments, edited the manuscript.

RP: Conceived the study, designed experiments, edited the manuscript.
All authors read and approved the final manuscript.

Funding Open access funding provided by Technical Research Centre of Finland (VTT). The study was funded by the Eurostars Project E!113904, with Canadian contributions from NRC-IRAP No. 944030 and Finnish contributions from Business Finland.

Data availability The Illumina reads generated in this study have been submitted to NCBI-SRA under BioProject number PRJNA740182 in the NCBI BioProject database (https://www.ncbi.nlm.nih.gov/biopr oject/).

\section{Declarations}

Conflict of interest Kristoffer Krogerus was employed by VTT Technical Research Centre of Finland Ltd. Eugene Fletcher and Richard Preiss were employed by Escarpment Laboratories Inc. Brian Gibson was employed by TU Berlin. Nils Rettberg was employed by VLB Berlin. The funders had no role in study design, data collection and analysis, decision to publish, or preparation of the manuscript.

Open Access This article is licensed under a Creative Commons Attribution 4.0 International License, which permits use, sharing, adaptation, distribution and reproduction in any medium or format, as long as you give appropriate credit to the original author(s) and the source, provide a link to the Creative Commons licence, and indicate if changes were made. The images or other third party material in this article are included in the article's Creative Commons licence, unless indicated otherwise in a credit line to the material. If material is not included in the article's Creative Commons licence and your intended use is not permitted by statutory regulation or exceeds the permitted use, you will need to obtain permission directly from the copyright holder. To view a copy of this licence, visit http://creativecommons.org/licenses/by/4.0/.

\section{References}

Alexander WG, Peris D, Pfannenstiel BT, Opulente DA, Kuang M, Hittinger CT (2016) Efficient engineering of marker-free synthetic allotetraploids of Saccharomyces. Fungal Genet Biol 89:10-17. https://doi.org/10.1016/j.fgb.2015.11.002

Alperstein L, Gardner JM, Sundstrom JF, Sumby KM, Jiranek V (2020) Yeast bioprospecting versus synthetic biology-which is better for innovative beverage fermentation? Appl Microbiol Biotechnol 104:1939-1953. https://doi.org/10.1007/s00253-020-10364-x

Aquilani B, Laureti T, Poponi S, Secondi L (2015) Beer choice and consumption determinants when craft beers are tasted: an exploratory study of consumer preferences. Food Qual Prefer 41:214224. https://doi.org/10.1016/j.foodqual.2014.12.005

Benaglia T, Chauveau D, Hunter DR, Young D (2009) mixtools : An $R$ package for analyzing finite mixture models. J Stat Softw 32:1-29. https://doi.org/10.18637/jss.v032.i06

Bonnaffoux H, Roland A, Schneider R, Cavelier F (2021) Spotlight on release mechanisms of volatile thiols in beverages. Food Chem 339:127628. https://doi.org/10.1016/j.foodchem.2020.127628

Capone DL, Barker A, Williamson PO, Francis IL (2018) The role of potent thiols in Chardonnay wine aroma. Aust J Grape Wine Res 24:38-50. https://doi.org/10.1111/ajgw.12294

Carbone A, Quici L (2020) Craft beer mon amour: an exploration of Italian craft consumers. Br Food J 122:2671-2687. https://doi.org/ 10.1108/BFJ-07-2019-0476 
Chen S, Zhou Y, Chen Y, Gu J (2018) fastp: an ultra-fast all-in-one FASTQ preprocessor. Bioinformatics 34:i884-i890. https://doi. org/10.1093/bioinformatics/bty560

Chenot C, Thibault de Chanvalon E, Janssens P, Collin S (2021) Modulation of the sulfanylalkyl acetate/alcohol ratio and free thiol release from cysteinylated and/or glutathionylated sulfanylalkyl alcohols in beer under different fermentation conditions. J Agric Food Chem 69:6005-6012. https://doi.org/10.1021/acs.jafc.1c016 10

Cibaka M-LK, Ferreira CS, Decourrière L, Lorenzo-Alonso C-J, Bodart E, Collin S (2017) Dry Hopping with the dual-purpose varieties Amarillo, Citra, Hallertau Blanc, Mosaic, and Sorachi Ace: minor contribution of hop terpenol glucosides to beer flavors. J Am Soc Brew Chem 75:122-129. https://doi.org/10.1094/ ASBCJ-2017-2257-01

Cingolani P, Platts A, Wang LL, Coon M, Nguyen T, Wang L, Land SJ, Lu X, Ruden DM (2012) A program for annotating and predicting the effects of single nucleotide polymorphisms, SnpEff: SNPs in the genome of Drosophila melanogaster strain w1118; iso-2; iso-3. Fly (austin) 6:80-92. https://doi.org/10.4161/fly. 19695

Coghe S, Benoot K, Delvaux F, Vanderhaegen B, Delvaux FR (2004) Ferulic acid release and 4-vinylguaiacol formation during brewing and fermentation: indications for feruloyl esterase activity in Saccharomyces cerevisiae. J Agric Food Chem 52:602-608. https://doi.org/10.1021/jf0346556

Cordente AG, Borneman AR, Bartel C, Capone D, Solomon M, Roach M, Curtin CD (2019) Inactivating mutations in Irc7p are common in wine yeasts, attenuating carbon-sulfur $\beta$-Lyase activity and volatile sulfur compound production. Appl Environ Microbiol 85:https://doi.org/10.1128/AEM.02684-18

Curtin C, Vega E, Cordente T, Fortmann K (2020) Mutations in carbon-sulfur B-lyase encoding gene IRC7 affect the polyfunctional thiol-releasing capability of brewers yeast. In: World Brewing Congress 2020

D'Hautcourt O, Smart K A. (1999) Measurement of brewing yeast flocculation. J Am Soc Brew Chem 57:123-128. https://doi.org/ 10.1094/ASBCJ-57-0129

De Chiara M, Barré B, Persson K, Chioma AO, Irizar A, Warringer J, Liti G (2020) Domestication reprogrammed the budding yeast life cycle. bioRxiv. https://doi.org/10.1101/2020.02.08.939314

Denis E, Sanchez S, Mairey B, Beluche O, Cruaud C, Lemainque A, Wincker P, Barbe V (2018) Extracting high molecular weight genomic DNA from Saccharomyces cerevisiae. Protoc Exch. https://doi.org/10.1038/protex.2018.076

Dennenlöhr J, Thörner S, Rettberg N (2020) Analysis of hop-derived thiols in beer using on-fiber derivatization in combination with HS-SPME and GC-MS/MS. J Agric Food Chem 68:1503615047. https://doi.org/10.1021/acs.jafc.0c06305

Dufour M, Zimmer A, Thibon C, Marullo P (2013) Enhancement of volatile thiol release of Saccharomyces cerevisiae strains using molecular breeding. Appl Microbiol Biotechnol 97:5893-5905. https://doi.org/10.1007/s00253-013-4739-7

Ellman GL (1958) A colorimetric method for determining low concentrations of mercaptans. Arch Biochem Biophys 74:443-450. https://doi.org/10.1016/0003-9861(58)90014-6

Engel SR, Dietrich FS, Fisk DG, Binkley G, Balakrishnan R, Costanzo MC, Dwight SS, Hitz BC, Karra K, Nash RS, Weng S, Wong ED, Lloyd P, Skrzypek MS, Miyasato SR, Simison M, Cherry JM (2014) The reference genome sequence of Saccharomyces cerevisiae: then and now. G3 (Bethesda) 4:389-98. https://doi.org/10.1534/g3.113.008995

Fischer S, Procopio S, Becker T (2013) Self-cloning brewing yeast: a new dimension in beverage production. Eur Food Res Technol 237:851-863. https://doi.org/10.1007/s00217-013-2092-9
Fukuda N, Kaishima M, Ishii J, Kondo A, Honda S (2016) Continuous crossbreeding of sake yeasts using growth selection systems for a-type and $\alpha$-type cells. AMB Express 6:45. https://doi.org/ 10.1186/s13568-016-0216-X

Gallone B, Steensels J, Prahl T, Soriaga L, Saels V, Herrera-Malaver B, Merlevede A, Roncoroni M, Voordeckers K, Miraglia L, Teiling C, Steffy B, Taylor M, Schwartz A, Richardson T, White C, Baele G, Maere S, Verstrepen KJ (2016) Domestication and divergence of Saccharomyces cerevisiae beer yeasts. Cell 166:1397-1410.e16. https://doi.org/10.1016/j.cell.2016.08.020

Garavaglia C, Swinnen J (2018) Economic perspectives on craft beer. Springer International Publishing, Cham

Garrison E, Marth G (2012) Haplotype-based variant detection from short-read sequencing. arXiv Prepr arXiv12073907 9. https:// doi.org/arXiv:1207.3907 [q-bio.GN]

Gel B, Serra E (2017) karyoploteR: an R/Bioconductor package to plot customizable genomes displaying arbitrary data. Bioinformatics 33:3088-3090. https://doi.org/10.1093/bioinformatics/btx346

Gonçalves M, Pontes A, Almeida P, Barbosa R, Serra M, Libkind D, Hutzler M, Gonçalves P, Sampaio JP (2016) Distinct domestication trajectories in top-fermenting beer yeasts and wine yeasts. Curr Biol 26:2750-2761. https://doi.org/10.1016/j.cub.2016.08. 040

Gonzalez Viejo C, Fuentes S (2020) Beer aroma and quality traits assessment using artificial intelligence. Fermentation 6:56. https:// doi.org/10.3390/fermentation6020056

Gorter de Vries AR, Couwenberg LGF, van den Broek M, de la Torre CP, ter Horst J, Pronk JT, Daran J-MG (2019) Allele-specific genome editing using CRISPR-Cas9 is associated with loss of heterozygosity in diploid yeast. Nucleic Acids Res 47:1362-1372. https://doi.org/10.1093/nar/gky1216

Gros J, Peeters F, Collin S (2012) Occurrence of odorant polyfunctional thiols in beers hopped with different cultivars. First evidence of an $S$-cysteine conjugate in hop (Humulus lupulus L.). J Agric Food Chem 60:7805-7816. https://doi.org/10.1021/jf301478m

Gunge N, Nakatomi Y (1972) Genetic mechanisms of rare matings of the yeast Saccharomyces cerevisiae heterozygous for mating type. Genetics 70:41-58

Haber JE (2012) Mating-Type genes and MAT switching in Saccharomyces cerevisiae. Genetics 191:33-64. https://doi.org/10.1534/ genetics.111.134577

Hahne F, LeMeur N, Brinkman RR, Ellis B, Haaland P, Sarkar D, Spidlen J, Strain E, Gentleman R (2009) flowCore: a bioconductor package for high throughput flow cytometry. BMC Bioinformatics 10:106. https://doi.org/10.1186/1471-2105-10-106

Herskowitz I (1988) Life cycle of the budding yeast Saccharomyces cerevisiae. Microbiol Rev 52:536-553

Hiraoka M, Watanabe KI, Umezu K, Maki H (2000) Spontaneous loss of heterozygosity in diploid Saccharomyces cerevisiae cells. Genetics 156:1531-1548. https://doi.org/10.1534/genetics.112. 541.test

Holt S, Miks MH, de Carvalho BT, Foulquié-Moreno MR, Thevelein JM (2019) The molecular biology of fruity and floral aromas in beer and other alcoholic beverages. FEMS Microbiol Rev 43:193222. https://doi.org/10.1093/femsre/fuy041

Howell KS, Swiegers JH, Elsey GM, Siebert TE, Bartowsky EJ, Fleet GH, Pretorius IS, Barros Lopes MA (2004) Variation in 4-mercapto-4-methyl-pentan-2-one release by Saccharomyces cerevisiae commercial wine strains. FEMS Microbiol Lett 240:125-129. https://doi.org/10.1016/j.femsle.2004.09.022

Huxley C, Green ED, Dunbam I (1990) Rapid assessment of S. cerevisiae mating type by PCR. Trends Genet 6:236. https://doi.org/10. 1016/0168-9525(90)90190-H 
Kassambara A (2020) ggpubr: "ggplot2" based publication ready plots. R package version 0.2. https://CRAN.R-project.org/packa ge $=$ ggpubr

Krogerus K, Arvas M, De Chiara M, Magalhães F, Mattinen L, Oja M, Vidgren V, Yue JX, Liti G, Gibson B (2016) Ploidy influences the functional attributes of de novo lager yeast hybrids. Appl Microbiol Biotechnol 100:7203-7222. https://doi.org/10. 1007/s00253-016-7588-3

Krogerus K, Holmström S, Gibson B (2018) Enhanced wort fermentation with de novo lager hybrids adapted to high-ethanol environments. Appl Environ Microbiol 84:e02302-e2317. https://doi.org/ 10.1128/AEM.02302-17

Krogerus K, Magalhães F, Kuivanen J, Gibson B (2019) A deletion in the STA1 promoter determines maltotriose and starch utilization in STA1+ Saccharomyces cerevisiae strains. Appl Microbiol Biotechnol 103:7597-7615. https://doi.org/10.1007/ s00253-019-10021-y

Krogerus K, Magalhães F, Vidgren V, Gibson B (2015) New lager yeast strains generated by interspecific hybridization. J Ind Microbiol Biotechnol 42:769-778. https://doi.org/10.1007/ s10295-015-1597-6

Krogerus K, Seppänen-Laakso T, Castillo S, Gibson B (2017) Inheritance of brewing-relevant phenotypes in constructed Saccharomyces cerevisiae x Saccharomyces eubayanus hybrids. Microb Cell Fact 16:66. https://doi.org/10.1186/s12934-017-0679-8

Legras JL, Karst F (2003) Optimisation of interdelta analysis for Saccharomyces cerevisiae strain characterisation. FEMS Microbiol Lett 221:249-255. https://doi.org/10.1016/S0378-1097(03) 00205-2

Li H (2011) A statistical framework for SNP calling, mutation discovery, association mapping and population genetical parameter estimation from sequencing data. Bioinformatics 27:2987-2993. https://doi.org/10.1093/bioinformatics/btr509

Li H, Durbin R (2009) Fast and accurate short read alignment with Burrows-Wheeler transform. Bioinformatics 25:1754-1760. https://doi.org/10.1093/bioinformatics/btp324

McMurrough I, Madigan D, Donnelly D, Hurley J, Doyle A, Hennigan G, McNulty N, Smyth MR (1996) Control of ferulic acid and 4-vinyl guaiacol in brewing. J Inst Brew 102:327-332. https:// doi.org/10.1002/j.2050-0416.1996.tb00918.x

Merlini L, Dudin O, Martin SG (2013) Mate and fuse: how yeast cells do it. Open Biol 3:130008. https://doi.org/10.1098/rsob.130008

Mertens S, Gallone B, Steensels J, Herrera-Malaver B, Cortebeek J, Nolmans R, Saels V, Vyas VK, Verstrepen KJ (2019) Reducing phenolic off-flavors through CRISPR-based gene editing of the FDC1 gene in Saccharomyces cerevisiae x Saccharomyces eubayanus hybrid lager beer yeasts. PLoS ONE 14:e0209124. https:// doi.org/10.1371/journal.pone.0209124

Mertens S, Steensels J, Gallone B, Souffriau B, Malcorps P, Verstrepen KJ (2017) Rapid screening method for phenolic off-flavor (POF) production in yeast. J Am Soc Brew Chem 75:318-323. https:// doi.org/10.1094/ASBCJ-2017-4142-01

Mertens S, Steensels J, Saels V, De Rouck G, Aerts G, Verstrepen KJ (2015) A large set of newly created interspecific Saccharomyces hybrids increases aromatic diversity in lager beers. Appl Environ Microbiol 81:8202-8214. https://doi.org/10.1128/AEM.02464-15

Michel M, Haslbeck K, Ampenberger F, Meier-Dörnberg T, Stretz D, Hutzler M, Coelhan M, Jacob F, Liu Y (2019) Screening of brewing yeast $\beta$-lyase activity and release of hop volatile thiols from precursors during fermentation. BrewingScience 72:179-186. https://doi.org/10.23763/BrSc19-26michel

Minh BQ, Nguyen MAT, Von Haeseler A (2013) Ultrafast approximation for phylogenetic bootstrap. Mol Biol Evol 30:1188-1195. https://doi.org/10.1093/molbev/mst024
Neiman AM (2011) Sporulation in the budding yeast Saccharomyces cerevisiae. Genetics 189:737-765. https://doi.org/10.1534/genet ics.111.127126

Nguyen LT, Schmidt HA, Von Haeseler A, Minh BQ (2015) IQ-TREE: a fast and effective stochastic algorithm for estimating maximumlikelihood phylogenies. Mol Biol Evol 32:268-274. https://doi. org $/ 10.1093 / \mathrm{molbev} / \mathrm{msu} 300$

Nikulin J, Krogerus K, Gibson B (2018) Alternative Saccharomyces interspecies hybrid combinations and their potential for low-temperature wort fermentation. Yeast 35:113-127. https://doi.org/10. 1002/yea.3246

Ota T, Kanai K, Nishimura H, Yoshida S, Yoshimoto H, Kobayashi O (2018) An efficient method for isolating mating-competent cells from bottom-fermenting yeast using mating pheromonesupersensitive mutants. Yeast 35:129-139. https://doi.org/10. 1002/yea.3291

Pedersen BS, Quinlan AR (2018) Mosdepth: quick coverage calculation for genomes and exomes. Bioinformatics 34:867-868. https:// doi.org/10.1093/bioinformatics/btx699

Pérez-Través L, Lopes CA, Barrio E, Querol A (2014) Stabilization process in Saccharomyces intra and interspecific hybrids in fermentative conditions. Int Microbiol 17:213-224. https:// doi.org/10.2436/20.1501.01.224

Peris D, Alexander WG, Fisher KJ, Moriarty RV, Basuino MG, Ubbelohde EJ, Wrobel RL, Hittinger CT (2020) Synthetic hybrids of six yeast species. Nat Commun 11:2085. https://doi. org/10.1038/s41467-020-15559-4

Peter J, De Chiara M, Friedrich A, Yue J-X, Pflieger D, Bergström A, Sigwalt A, Barre B, Freel K, Llored A, Cruaud C, Labadie K, Aury J-M, Istace B, Lebrigand K, Barbry P, Engelen S, Lemainque A, Wincker P, Liti G, Schacherer J (2018) Genome evolution across 1,011 Saccharomyces cerevisiae isolates. Nature 556:339-344. https://doi.org/10.1038/ s41586-018-0030-5

Pfaffl MW (2001) A new mathematical model for relative quantification in real-time RT-PCR. Nucleic Acids Res 29:45e-445. https://doi. org/10.1093/nar/29.9.e45

Rantasalo A, Kuivanen J, Penttilä M, Jäntti J, Mojzita D (2018) Synthetic toolkit for complex genetic circuit engineering in Saccharomyces cerevisiae. ACS Synth Biol 7:1573-1587. https://doi.org/ 10.1021/acssynbio.8b00076

Roland A, Viel C, Reillon F, Delpech S, Boivin P, Schneider R, Dagan L (2016) First identification and quantification of glutathionylated and cysteinylated precursors of 3-mercaptohexan-1-ol and 4-methyl-4-mercaptopentan-2-one in hops ( Humulus lupulus ). Flavour Fragr J 31:455-463. https://doi.org/10.1002/ffj.3337

Roncoroni M, Santiago M, Hooks DO, Moroney S, Harsch MJ, Lee SA, Richards KD, Nicolau L, Gardner RC (2011) The yeast IRC7 gene encodes a $\beta$-lyase responsible for production of the varietal thiol 4-mercapto-4-methylpentan-2-one in wine. Food Microbiol 28:926-935. https://doi.org/10.1016/j.fm.2011.01.002

Ruiz J, Celis M, Martín-Santamaría M, Benito-Vázquez I, Pontes A, Lanza VF, Sampaio JP, Santos A, Belda I (2021) Global distribution of IRC7 alleles in Saccharomyces cerevisiae populations: a genomic and phenotypic survey within the wine clade. Environ Microbiol 23:3182-3195. https://doi.org/10.1111/1462-2920. 15540

Scott AL, Richmond PA, Dowell RD, Selmecki AM (2017) The influence of polyploidy on the evolution of yeast grown in a sub-optimal carbon source. Mol Biol Evol 34:2690-2703. https://doi.org/ 10.1093/molbev/msx205

Selmecki AM, Maruvka YE, Richmond P, a, Guillet M, Shoresh N, Sorenson AL, De S, Kishony R, Michor F, Dowell R, Pellman $\mathrm{D}$, (2015) Polyploidy can drive rapid adaptation in yeast. Nature 519:349-352. https://doi.org/10.1038/nature14187 
Shimoi H, Kawamura N, Yamada M (2020) Cloning of the SPO11 gene that complements a meiotic recombination defect in sake yeast. J Biosci Bioeng 130:367-373. https://doi.org/10.1016/j. jbiosc.2020.06.005

Steensels J, Meersman E, Snoek T, Saels V, Verstrepen KJ (2014) Large-scale selection and breeding to generate industrial yeasts with superior aroma production. Appl Environ Microbiol 80:6965-6975. https://doi.org/10.1128/AEM.02235-14

Tarasov A, Vilella AJ, Cuppen E, Nijman IJ, Prins P (2015) Sambamba: fast processing of NGS alignment formats. Bioinformatics 31:2032-2034. https://doi.org/10.1093/bioinformatics/btv098

Thibon C, Marullo P, Claisse O, Cullin C, Dubourdieu D, Tominaga $\mathrm{T}$ (2008) Nitrogen catabolic repression controls the release of volatile thiols by Saccharomyces cerevisiae during wine fermentation. FEMS Yeast Res 8:1076-1086. https://doi.org/10.1111/j. 1567-1364.2008.00381.x

Tripp JD, Lilley JL, Wood WN, Lewis LK (2013) Enhancement of plasmid DNA transformation efficiencies in early stationary-phase yeast cell cultures. Yeast 30:191-200. https://doi.org/10.1002/yea. 2951

Vanbeneden N, Gils F, Delvaux F, Delvaux FR (2008) Formation of 4-vinyl and 4-ethyl derivatives from hydroxycinnamic acids: occurrence of volatile phenolic flavour compounds in beer and distribution of Pad1-activity among brewing yeasts. Food Chem 107:221-230. https://doi.org/10.1016/j.foodchem.2007.08.008

Xie Z-X, Mitchell LA, Liu H-M, Li B-Z, Liu D, Agmon N, Wu Y, Li X, Zhou X, Li B, Xiao W-H, Ding M-Z, Wang Y, Yuan Y-J, Boeke JD (2018) Rapid and efficient CRISPR/Cas9based mating-type switching of Saccharomyces cerevisiae. G3 Genes|Genomes|Genetics 8:173-183. https://doi.org/10.1534/g3. 117.300347

Yu G, Smith DK, Zhu H, Guan Y, Lam TT (2017) ggtree: an r package for visualization and annotation of phylogenetic trees with their covariates and other associated data. Methods Ecol Evol 8:28-36. https://doi.org/10.1111/2041-210X.12628

Publisher's note Springer Nature remains neutral with regard to jurisdictional claims in published maps and institutional affiliations. 